\title{
Rossby Wave Initiation by Recurving Tropical Cyclones in the Western North Pacific
}

\author{
JACOPO RIBOLDI \\ Institute for Atmospheric and Climate Science, ETH Zurich, Zurich, Switzerland \\ MATTHIAS RÖTHLISBERGER \\ Institute of Geography, Oeschger Centre for Climate Change Research, University of Bern, Bern, Switzerland \\ CHRISTIAN M. GRAMS ${ }^{\mathrm{a}}$ \\ Institute for Atmospheric and Climate Science, ETH Zurich, Zurich, Switzerland
}

(Manuscript received 31 July 2017, in final form 7 March 2018)

\begin{abstract}
The interaction of recurving tropical cyclones (TCs) with midlatitude Rossby waves during extratropical transition (ET) can significantly alter the midlatitude flow configuration. This study provides a climatological investigation of Rossby wave initiation (RWI) by transitioning TCs in the specific configuration of an initially zonal midlatitude waveguide and elucidates physical processes governing ab initio flow amplification during ET. Recurving TCs interacting with a zonally oriented waveguide in the western North Pacific (WNP) basin from 1979 to 2013 are categorized into cases initiating Rossby waves (TC-RWI) or not (TC-noRWI). Interactions with a zonally oriented waveguide occurred for $22.7 \%$ of the recurving TCs, and one-third of these resulted in TC-RWI. In the presence of a TC, the probability of RWI on a zonally oriented waveguide is 3 times larger than in situations without a TC. The occurrence of TC-RWI exhibits a seasonality and is relatively more common during boreal summer than in autumn. We further reveal that a strong preexisting upper-level jet stream, embedded in a deformative large-scale flow pattern, hinders TC-RWI as air from the diabatic outflow of the TC is rapidly advected downstream and does not lead to strong ridge building. In contrast, an enhanced monsoon trough favors TC-RWI as the poleward moisture transport strengthens diabatic outflow and leads to strong ridge building during ET. Thus, we conclude that TC-related ab initio flow amplification over the WNP is governed by characteristics of the large-scale flow more so than by characteristics of the recurving TC.
\end{abstract}

\section{Introduction}

Rossby wave packets (e.g., Lee and Held 1993; Wolf and Wirth 2017) are constituted by couplets of potential vorticity $(\mathrm{PV})$ anomalies propagating along regions of strong PV gradient, which act as a waveguide (Hoskins

Supplemental information related to this paper is available at the Journals Online website: https://doi.org/10.1175/MWR-D-170219.s1.

\footnotetext{
${ }^{a}$ Current affiliation: Institute of Meteorology and Climate Research (IMK-TRO), Karlsruhe Institute of Technology, Karlsruhe, Germany.
}

Corresponding author: Jacopo Riboldi, jacopo.riboldi@env.ethz.ch and Ambrizzi 1993; Martius et al. 2010). Rossby waves are tightly connected with the genesis and intensification of extratropical cyclones and with the occurrence of high-impact weather in the extratropics (e.g., Hoskins et al. 1985; Massacand et al. 1998; Screen and Simmonds 2014; Röthlisberger et al. 2016b; Barton et al. 2016). The growing phase of Rossby waves is pivotal for weather forecasting as forecast errors propagate and amplify with the waves themselves (Hakim 2005; Davies and Didone 2013; Grazzini and Vitart 2015). Hence, it is interesting to study how such waves are initiated. Röthlisberger et al. (2016a) pointed out that Rossby waves can be initiated by a variety of different phenomena, such as interactions between the polar and the subtropical jet (Martius et al. 2010), or by the presence of mesoscale convective systems (Rodwell et al. 2013; Stensrud 2013; Röthlisberger et al. 2016a), by so-called 
tropopause polar vortices (Cavallo and Hakim 2009), by warm conveyor belts (WCBs) in forming extratropical cyclones (Madonna et al. 2014; Martínez-Alvarado et al. 2016; Röthlisberger et al. 2018), and by tropical cyclones (TCs) approaching the waveguide. This last process is the focus of this study, which aims to quantify, from a climatological perspective, the relationship between recurving TCs and Rossby wave initiation (RWI).

Recurving TCs can act as a source of kinetic energy for the midlatitude circulation (Harr and Dea 2009; Hart 2011; Keller et al. 2014) and promote meridional displacements of the jet stream axis (Klein et al. 2002), especially during the process of extratropical transition (ET; e.g., Harr and Archambault 2016). Latent heat release in the region of the transitioning TC allows low$\mathrm{PV}$ air to move from the lower to the upper troposphere (Grams et al. 2013a; Winters and Martin 2016), thereby reducing static stability and $\mathrm{PV}$ at the equatorward side of the jet. This can promote frontogenesis at the level of the tropopause (Lang and Martin 2013).

Furthermore, this low-PV air is advected to the jet by the diabatically induced outflow of the TC or of other mesoscale weather systems in the vicinity of the recurving TC (Agustí-Panareda et al. 2004; Grams and Archambault 2016). The resulting increase in the PV gradient at the tropopause accelerates the jet stream, while the aforementioned diabatic outflow meridionally displaces the jet poleward and initiates ridge building (Atallah and Bosart 2003; Archambault et al. 2015). This is often followed by the elongation of a trough at the eastern side of the ridge that promotes downstream cyclogenesis, following the archetypal paradigm of downstream development (Orlanski and Sheldon 1995; Riemer et al. 2014), which can lead to a second ridge building farther downstream. We will refer to this set of processes (i.e., formation of a jet streak, its meridional displacement, and downstream baroclinic development) as "flow amplification."

Most of the previous research about flow amplification by ET has focused on the interaction between recurving TCs and preexisting Rossby waves. It has been shown that TC-Rossby wave interactions determine the occurrence of extratropical reintensification during ET (e.g., Harr et al. 2000; Ritchie and Elsberry 2007) and influence the amplitude of the downstream Rossby wave pattern after the interaction. Sensitivity studies showed that ET can enhance or diminish the amplitude of the Rossby waves interacting with the transitioning TC (e.g., AgustíPanareda et al. 2005; Grams et al. 2013b; Riemer and Jones 2014). The linkage among ET, preexisting Rossby waves, diabatic processes, and downstream flow amplification has also been established by various climatological studies about the western North Pacific (WNP) basin.
TCs recurving ahead of an upper-level (UL) trough were linked with a large-amplitude, long-lasting, statistically significant downstream response (Torn and Hakim 2015). This relationship holds in the opposite direction, too: strong interactions with the midlatitude flow or positive anomalies in Rossby wave packet amplitude and frequency downstream of ET were robustly linked to the presence of an upstream UL trough (Archambault et al. 2015; Quinting and Jones 2016).

The presence of a UL trough upstream of the transitioning TC is a common feature across the outlined studies, and its connection with storm reintensification and long-lasting downstream flow amplification is well established. However, TC-midlatitude flow interactions also encompass other synoptic configurations: interaction between a TC and a low-amplitude upstream trough (Archambault et al. 2015; Torn and Hakim 2015) or with a trough located downstream of the recurving TC (Harr et al. 2000; Grams et al. 2013b) or with a zonally oriented jet where preexisting Rossby waves are not present (Riemer et al. 2008).

Interactions between TCs and zonally oriented waveguides have been discussed mainly in idealized studies. So far, Riemer et al. (2008) described how a strong TC is able to initiate Rossby waves on a zonally oriented jet stream. Scheck et al. (2011) illustrated, in a fully barotropic framework, how a TC acts as a slowmoving Rossby wave maker and defined a resonance condition for sustained flow amplification. Using piecewise PV inversion, Riemer et al. (2008) attributed flow amplification to the presence of diabatic outflow and to the cyclonic circulation of the TC. Additionally, they described how the strength of the jet stream was inversely proportional to the intensity of flow amplification.

The relevance of recurving TCs for RWI occurring in close proximity to the TC has never been assessed in a climatological sense. Among the various TC basins, the WNP likely features the largest number of such events, because zonally oriented jet streams occur there frequently (Röthlisberger et al. 2018) and often result from a superposition of the polar and subtropical jet (Handlos and Martin 2016). Furthermore, previous studies about ET dealt with complex configurations of TC-flow interaction, where small differences in, for example, relative position of the TC with respect to an approaching UL trough can lead to drastically different flow evolutions (e.g., Grams et al. 2013b; Galarneau 2015; Pantillon et al. 2016). Therefore, the simplified situation of a TC interacting with an unperturbed waveguide should be particularly well-suited to identify the factors that discriminate between cases leading to flow amplification and those that do not. 
The objective of this study is the systematic investigation of TC-midlatitude flow interactions in the absence of a preamplified flow (i.e., featuring only lowamplitude UL troughs and ridges). We combine two previously published methodologies to identify zonally oriented segments of the jet stream co-occurring with recurving TCs in the WNP (section 2). This allows developing a climatology of interactions between TCs and zonally oriented jet streams (section 3 ). We then discuss their synoptic environment and contrast them with interactions that did not result in RWI (section 4). Conclusions are finally summarized in section 5 .

\section{Data and methodology}

This study is based on ECMWF interim reanalysis (ERA-Interim) data (Dee et al. 2011) at $1^{\circ} \times 1^{\circ}$ horizontal resolution and using 6-hourly temporal resolution. ERA-Interim model-level data are interpolated to nine isentropic levels between and including 315 and $355 \mathrm{~K}$ (every $5 \mathrm{~K}$ ). The IBTrACS dataset (Knapp et al. 2010) is used to provide information on TC tracks and intensity in the WNP between 1979 and 2013. Recurving TCs are detected following Archambault et al. (2013): recurvature is defined as a change in the direction of a TC moving northward, at the westernmost point of its track below $45^{\circ} \mathrm{N}$, where the TC stops heading westward and starts moving eastward. Unlike in Archambault et al. (2013)'s study, TCs tracking in a loop are not excluded. This definition of recurvature results in the objective identification of 331 recurving TCs.

\section{a. Definition of RWI segments}

The occurrence of flow amplification is assessed using the contour-based RWI detection method developed by Röthlisberger et al. (2016a).

The algorithm analyzes 2-PVU (1 PVU $=10^{-6} \mathrm{~K} \mathrm{~kg}^{-1}$ $\mathrm{m}^{2} \mathrm{~s}^{-1}$ ) isolines at various isentropic levels between 320 and $340 \mathrm{~K}$ in the Northern Hemisphere: contours of 2 PVU are divided into 120 segments starting every $3^{\circ}$ of longitude. Each segment spans a $60^{\circ}$ longitude sector and consists of $N_{j}$ longitude-latitude points $\left(\lambda_{i}, \phi_{i}\right.$, $\left.i=1, \ldots, N_{j}\right)$, with consecutive grid points separated by approximately $50 \mathrm{~km}$. Isentropic levels are selected for each month as the ones on which the average PV gradient magnitude between $35^{\circ}$ and $65^{\circ} \mathrm{N}$ is largest (Röthlisberger et al. 2018). They range from $320 \mathrm{~K}$ in the months from December to March to $340 \mathrm{~K}$ in July and August and progress in 5-K steps across the other months (i.e., $325 \mathrm{~K}$ in April and November, $330 \mathrm{~K}$ in May and October, and $335 \mathrm{~K}$ in June and September). A given contour segment is labeled as an "RWI segment" if it satisfies three criteria: 1) it is sufficiently zonal, 2) no large-amplitude waves are present upstream of the segment, and 3) its waviness rapidly increases with time.

The zonality criterion is first tested using a waviness metric. The waviness $d$ of a contour segment at a given time is defined as the sum of the absolute latitude differences between the consecutive points of the segment [see Eq. (1) in Röthlisberger et al. (2016a)]:

$$
d=\sum_{i=1}^{N_{j}-1}\left|\phi_{i+1}-\phi_{i}\right| .
$$

In this study, 2-PVU contour segments with a waviness below $d_{\max }=16^{\circ}$ are considered zonally oriented, or "straight," at a given time (first RWI criterion). This threshold is more stringent (i.e., $4^{\circ}$ lower) than the original one used in Röthlisberger et al. (2016a, 2018). Therefore, the amplitude of the allowed undulations on zonal contour segments is further reduced. As a reference, the maximum allowed amplitude of a single ridge-trough couplet in a straight $60^{\circ}$-long segment is only $4^{\circ}$ (see online supplemental material). A visual inspection of the cases identified using the $20^{\circ}$ threshold revealed that some of them could not be considered "ab initio" flow amplification related to the presence of a recurving TC (not shown). Therefore, a more conservative choice of $d_{\max }$ than in Röthlisberger et al. (2016a) was needed.

An increase in waviness in an originally zonal contour segment might result from waves propagating into that segment from upstream. Therefore, the RWI identification algorithm discards zonal contour segments if the waviness in one of the contour segments starting in the $45^{\circ}$ longitude range upstream of the candidate segment exceeds the waviness of the candidate segment by more than $4^{\circ}$ (second RWI criterion). After having verified that there is no upstream disturbance affecting the waviness of the segment, any waviness change must be related to processes occurring along the segment of interest. Finally, if the time-averaged increase of $d$ exceeds $8^{\circ}$ within $30 \mathrm{~h}$, an RWI segment is detected [third RWI criterion; see Eq. (2) in Röthlisberger et al. (2016a)]. This method most reliably identifies RWI segments in which the initiated waves grow rapidly. However, segments with particularly slow wave amplification are not always identified, even though some meteorologists might consider them RWI segments as well. Here, we found only a few problematic cases; therefore, we stick to the objective methodology rather than filtering manually. All cases are listed in the online supplemental material (Tables S1, S2). 


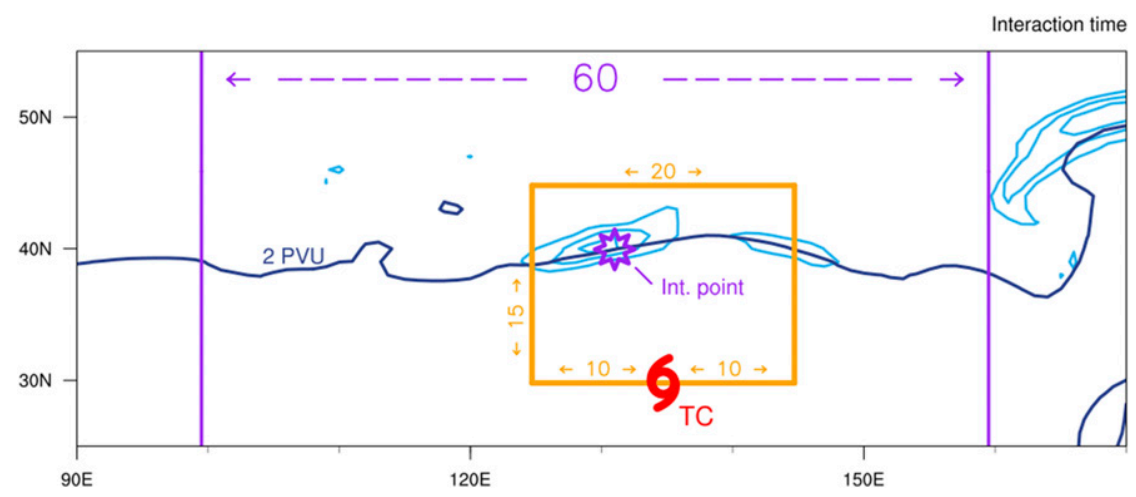

FIG. 1. Determination of the interaction point between the TC and the waveguide at $t_{\text {int }}$ for Typhoon Sperry (0000 UTC1 Jul 1987). Light blue contours depict areas of negative PV advection by the irrotational wind (only $-5,-10$, and $-15 \mathrm{PVU} \mathrm{day}^{-1}$ ). The interaction point, located on the 2-PVU contour at the point of minimum PV advection by the irrotational wind, is highlighted by the purple star. The thick, dark blue line depicts the 2-PVU contour on the 340-K isentropic level, and the $60^{\circ}$-interaction segment is highlighted between the two vertical purple lines. Dimension of the boxes and length of the segment are in degrees of latitude and longitude.

Further details on the RWI detection algorithm and about the employed thresholds, together with a schematic, are given in Röthlisberger et al. (2016a).

\section{b. Characterization of TC-straight jet interactions}

We classify the considered set of recurving TCs into four subsets. If the first RWI criterion (zonality) is not satisfied, then TCs interact with a wavy flow while moving toward midlatitudes ("TC-wavy jet"). If only the first RWI criterion is satisfied, TCs approach a zonally oriented 2-PVU contour segment that exhibits high waviness upstream ("TC-wavy upstream"). If the second RWI criterion (absence of upstream waviness) is met, too, the recurving TC is part of a "TC-straight jet interaction" (TCSJI). In this case, we determine a location of interaction, a time of interaction, and a segment of interaction using the PV advection by the irrotational wind [similarly to Archambault et al. (2013), as described below]. The set of TCSJIs can be further split between TCs leading to RWI ("TC-RWI") and not leading to RWI ("TC-noRWI") according to the fulfillment of the third RWI criterion (sufficient waviness increase).

The TC is said to interact with the jet stream at a given time step if the 2-PVU isoline at the considered isentropic level is located close enough to the IBTrACS position of the storm, that is, intersecting a $20^{\circ} \times 15^{\circ}$ longitude-latitude box north of the TC's position (orange in Fig. 1). The choice of this box reflects the fact that almost all locations of maximum interaction fell in this range with respect to the TC's position [Archambault et al. (2015), their Fig. 2].

All time steps when the considered 2-PVU isoline intersects the box are considered candidate time steps $t_{\text {cand }}$ for interaction. For every $t_{\text {cand }}$, we determine a candidate interaction point along the contour: it is defined as the point where the absolute value of the negative PV advection by the irrotational wind is maximized along the section of the 2-PVU contour intersecting the orange box of Fig. 1. This section must span at least $5^{\circ}$ of longitude in order to avoid spurious detection when the orange box only marginally intersects the 2-PVU contour. Furthermore, the PV advection by the irrotational wind, averaged in a $15^{\circ} \times 15^{\circ}$ longitude-latitude box centered at the candidate interaction point, must be negative. If this candidate interaction point is part of a contour segment that fulfills the first two RWI criteria and additionally extends at least $20^{\circ}$ downstream of the point of interaction, the event is classified as a TCSJI. The first time step when all the aforementioned criteria are met is defined as the time of interaction $t_{\text {int }}$, and the time span between $t_{\text {int }}$ and $t_{\text {int }}+30 \mathrm{~h}$ is defined as the interaction period $\Delta t_{\text {int }}$. The candidate interaction point at $t_{\text {int }}$ is labeled as the location of interaction. As the contour segments are overlapping, it is possible that more than one contour segment fulfills all the criteria: in such cases, the segment extending most downstream is chosen.

All TCSJIs occurring in RWI segments, that is, where the third RWI criterion is also satisfied at least for one time step $t_{\text {cand }}$, are considered TC-RWI events. On the other hand, TCSJIs that do not satisfy the third criterion are labeled as TC-noRWI events.

\section{c. Integrated water vapor transport and warm conveyor belts}

We conclude this section with the description of some quantities related to moisture transport and diabatic processes. 
TABLE 1. Absolute numbers and frequencies of objectively classified recurving TC-waveguide interactions in the IBTrACS (1979-2013) dataset.

\begin{tabular}{llcc}
\hline \hline Shape of waveguide & \multicolumn{1}{c}{$\begin{array}{c}\text { Type of } \\
\text { interaction }\end{array}$} & $\begin{array}{c}\text { No. of } \\
\text { TCs }\end{array}$ & $\begin{array}{c}\text { Relative } \\
\text { percentage (\%) }\end{array}$ \\
\hline Preamplified flow & TC-wavy jet & 149 & 45.0 \\
& TC-wavy upstream & 107 & 32.3 \\
\multirow{2}{*}{ Zonally oriented jet } & TC-noRWI & 52 & 15.7 \\
& TC-RWI & 23 & 7.0 \\
\hline
\end{tabular}

Moisture flux is defined as MF $=q \mathbf{V}_{h}$, where $q$ is the specific humidity, and $\mathbf{V}_{h}=(u, v)$ is the $2 \mathrm{D}$ horizontal wind vector interpolated on surfaces of constant pressure. The column-integrated moisture flux provides the integrated water vapor transport (IVT),

$$
\mathrm{IVT}=\frac{1}{g} \sqrt{\left(\int_{p=1000 \mathrm{hPa}}^{p=0 \mathrm{hPa}} q u d p\right)^{2}+\left(\int_{p=100 \mathrm{hPa}}^{p=0 \mathrm{hPa}} q v d p\right)^{2}}
$$

which is expressed in units of kilograms per meter per second.

WCBs are composed by air parcels ascending more than $600 \mathrm{hPa}$ in less than $48 \mathrm{~h}$ in the vicinity of a surface pressure minimum [following the definition of Madonna et al. (2014)]. WCBs are a typical feature of extratropical cyclones, but the employed definition encompasses a broad spectrum of rapidly ascending air parcels: for example, the ones belonging to TCs or to large-scale convective systems. The dataset of outflow WCB trajectories (i.e., located at a pressure $p<400 \mathrm{hPa}$ ) described in Sprenger et al. (2017) is employed in this study to highlight the presence of diabatic outflow at the level of the jet stream.

\section{A climatology of TC-straight jet interactions}

The set of TCSJIs is analyzed to explore how often these events occur, to describe the associated synoptic situation, and to disentangle the relative roles of the TC and of the extratropical flow in the occurrence of RWI.

\section{a. Frequency and seasonality}

In total, 331 WNP recurving TCs have been investigated (Table 1). Fewer than half of these (149 out of 331 ) interacted with an entirely wavy jet stream (TCwavy jet; none of the RWI criteria fulfilled during any $t_{\text {cand }}$ ), while 107 approached a zonally oriented segment of the jet downstream of a large-amplitude wave packet (TC-wavy upstream; only first RWI criterion fulfilled).
These numbers confirm findings of previous climatological studies that highlight the typical presence of a preamplified UL flow during the recurvature of WNP TCs and, in particular, of an upstream trough (e.g., Archambault et al. 2015; Torn and Hakim 2015; Quinting and Jones 2016).

The remaining 75 cases $(22.7 \%$ of the total) feature an extended, zonally oriented waveguide (fulfilling the first and second RWI criteria), and these constitute the analyzed set of TCSJIs (see also Tables S1, S2). This set of interactions contains a substantial fraction of the recurving TCs and differs from the archetypal pattern of a TC interacting with a UL trough during ET. On average, 2.1 TCSJIs happen every year, with a moderate interannual variability (Fig. 2a). Most of the years feature the occurrence of 1-3 TCSJIs, and only during 4 years (1993, 1997, 2002, and 2006) was no TCSJI detected. TCSJIs occur during the entire typhoon season and are more common between August and October (Fig. 2b).

The annual frequency of TCSJIs is considerably lower than the one of "no trough" cases described by Torn and Hakim (2015) (22.7\% vs $48 \%$ ). This is most likely due to the different criteria adopted in the current study. Our method requires that the interaction segment exhibit low waviness in the $45^{\circ}$ upstream of the segment itself [equivalent to about $4000 \mathrm{~km}$, compared to about $1000 \mathrm{~km}$ in Torn and Hakim (2015)]. Furthermore, the interaction segment must extend at least $20^{\circ}$ downstream of the interaction point. Overall, our upstream trough detection can be considered more conservative than the one of Torn and Hakim (2015). However, our approach focuses on the midlatitude waveguide only and may face challenges during times when multiple and clearly distinct waveguides are present at the same longitude. Segments fulfilling the zonality criterion on the considered isentropic level do not need to be zonal on lower isentropic levels (representing the polar waveguide), and disturbances on those levels could affect Rossby wave dynamics also on the midlatitude waveguide. However, Martius et al. (2010) showed that typically, such an interaction between waveguides only occurs in the case of Rossby wave breaking. Hence, an even more stringent upstream criterion, taking into account different waveguides, would likely not exclude cases significantly affected by downstream development initiated on lower levels and, additionally, would further reduce the overall number of TCSJIs.

Of the 75 TCSJIs, 23 led to TC-RWI (Table 1). The small sample size demands caution when interpreting this result, but nevertheless, RWI segments linked to recurving TCs in the WNP tend to occur more often during boreal summer (JJA; 10 events out of 16) than in fall (SON; 11 events out of 52). This is noteworthy from the point of 
(a) Inter-annual variability

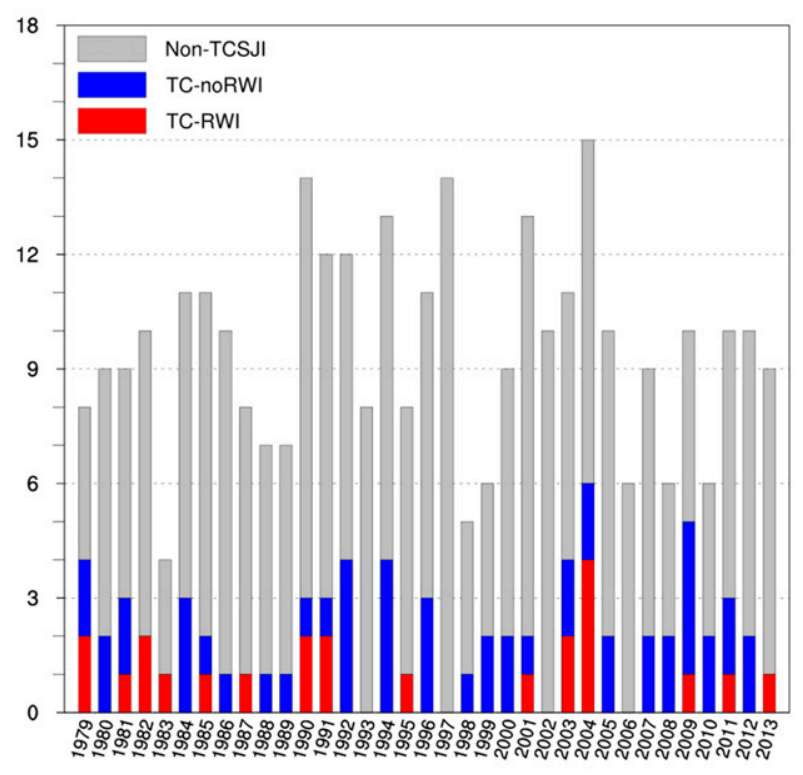

(b) Monthly variability

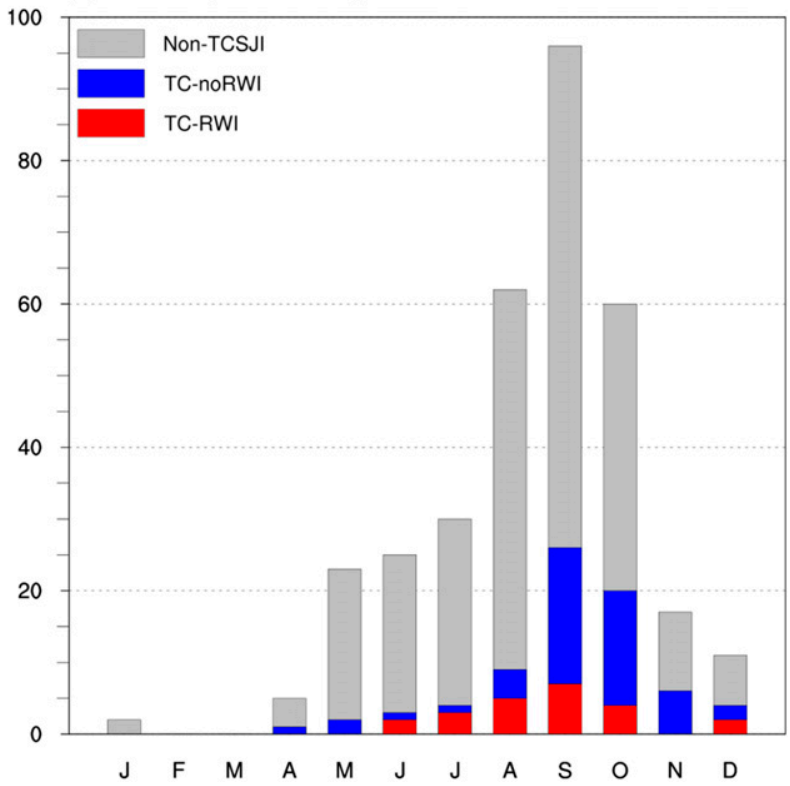

FIG. 2. Number of WNP recurving TCs between 1979 and 2013, stratified according to (a) year and (b) month of interaction, split between non-TCSJI (gray) and TCSJI events. The latter are divided into TC-RWI (red) and TC-noRWI (blue).

view of RWI, as RWI occurs much less frequently in that area during JJA than SON (Röthlisberger et al. 2018). Furthermore, the outlined RWI seasonality suggests that flow amplification downstream of ET may be stronger in summer than in autumn: this would be consistent with the results of previous climatological studies (Archambault et al. 2013; Quinting and Jones 2016), although they did not focus specifically on synoptic configurations of weakly amplified flow. Some hypotheses to explain this seasonality in the occurrence of TC-RWI will be discussed in section 4a.

As pointed out before, TCSJIs resulted in TC-RWI in almost one-third of the cases (23 of $75 ; 30.6 \%$ ). Climatologically, RWI segments in the North Pacific area (i.e., starting at longitudes between $90^{\circ} \mathrm{E}$ and $150^{\circ} \mathrm{W}$ ) make up $11.8 \%$ of all contour segments that fulfill only the first two RWI criteria in that region. This number varies between $9.5 \%$ and $14 \%$ throughout the year (Table 2). Thus, for zonal jets without upstream waves, RWI is 3 times more likely to occur in the presence of a TC than in climatology. This corroborates the assumption that recurving TCs can act as effective initiators of extratropical Rossby waves.

The differences between TC-RWI and TC-noRWI cases will be the focus of the next sections.

\section{b. Synoptic environment of TCSJIs: A composite view}

The synoptic environment of the identified TC-RWI and TC-noRWI events is analyzed using time-lagged composites centered on the location and time of interaction (Figs. 3, 4). In the remainder of this section, we elucidate differences between the composites in four key aspects: characteristics of the jet stream and of the largescale flow pattern, intensity of meridional moisture transport, and presence of irrotational wind and of WCB trajectories at outflow level (i.e., $<400 \mathrm{hPa}$ ).

Generally, TCSJIs prior to $t_{\text {int }}$ feature a broad, zonally oriented jet stream along the interaction segment, with peak wind speed (in a composite sense) near $45 \mathrm{~m} \mathrm{~s}^{-1}$ (Figs. 3a, 4a). This jet is broader and slightly stronger in the TC-noRWI subset than in TC-RWI (see the different extension of the $45 \mathrm{~m} \mathrm{~s}^{-1}$ isotach). A surface cyclone near the poleward exit region of the jet is also present in both cases, but it is wider and located farther downstream in the TCnoRWI composite (Figs. 3a, 4a). Furthermore, a surface anticyclone is present to the northwest of the TC in the TCnoRWI subset only. TCs are embedded in a low-level monsoon trough (as reflected in a broad region of low SLP and high IVT extruding from low latitudes; Figs. 3a-d, 4a-d). The synoptic configuration in TC-noRWI (anticyclones to the northwest and southeast, cyclones to the southwest and northeast of the jet maximum) highlights the presence of a large-scale deformation pattern, which persists through the interaction (Fig. 4, left column). We can hypothesize that this flow pattern enhances the PV gradient along the interaction segment and contributes to the higher jet speed in the TC-noRWI subset (Davies and Rossa 1998). Additionally, TCs leading to RWI are 
TABLE 2. Monthly numbers of segments fulfilling the first two RWI criteria (zonality, no upstream wave) and RWI segments (all three RWI criteria) starting in the North Pacific between $90^{\circ} \mathrm{E}$ and $150^{\circ} \mathrm{W}$ and ratio between the two in the period 1979-2013.

\begin{tabular}{lccc}
\hline Month & $\begin{array}{c}\text { Zonally oriented } \\
\text { segments }\end{array}$ & $\begin{array}{c}\text { RWI } \\
\text { segments }\end{array}$ & $\begin{array}{c}\text { Relative } \\
\text { percentage (\%) }\end{array}$ \\
\hline Jan & 7982 & 952 & 11.9 \\
Feb & 6468 & 837 & 12.9 \\
Mar & 3343 & 370 & 11.1 \\
Apr & 2619 & 304 & 11.6 \\
May & 2182 & 208 & 9.5 \\
Jun & 2207 & 222 & 10.1 \\
Jul & 718 & 69 & 9.6 \\
Aug & 1381 & 174 & 12.6 \\
Sep & 4147 & 507 & 12.2 \\
Oct & 5278 & 577 & 10.9 \\
Nov & 5290 & 574 & 10.9 \\
Dec & 5731 & 805 & 14.0 \\
Total & 47346 & 5599 & 11.8 \\
\hline
\end{tabular}

associated with a stronger moisture transport than TCnoRWI, as highlighted by the more extended area of strong IVT (i.e., $>400 \mathrm{~kg} \mathrm{~m}^{-1} \mathrm{~s}^{-1}$; Figs. 3b, 4b). The moister environment is also apparent from the different WCB activity, which is almost absent in TC-noRWI (Fig. 4b).

At $t_{\text {int }}$, the TCs approach the waveguide from the south, and the jet maximum is now located just downstream of the interaction point in both subsets. The jet maximum is also located to the north of a maximum in WCB activity in a region of strong irrotational outflow (Figs. 3c, 4c). This is associated with the advection of low-PV air at the equatorward side of the jet, which promotes a local strengthening of the PV gradient and an increase in jet speed. TCSJIs belonging to the TCnoRWI subset feature a broader jet (both in the zonal and meridional direction) and a maximum speed $5 \mathrm{~m} \mathrm{~s}^{-1}$ higher (in a composite sense) than the TC-RWI cases (Fig. 4c). WCB outflow and irrotational wind are present in the vicinity of the interaction point, albeit slightly weaker than in the TC-RWI subset (Figs. 3d, 4d).

Despite the concomitant presence of WCB trajectories and irrotational outflow at $t_{\text {int }}$ in both TC-RWI and TCnoRWI, the resulting perturbation to the waveguide $24 \mathrm{~h}$ after $t_{\text {int }}$ differs for the two subsets. A ridge has formed downstream of the interaction point in the TC-RWI composite (Fig. 3e). Ridge building downstream of the TC is linked to the persisting frequency maximum of WCB trajectories and to the irrotational wind near the TC outflow region, which was already present at $t_{\text {int }}$ (Fig. 3f). The broad region of enhanced IVT to the east of the TC in the TCRWI composite (Fig. 3f) is now connected to a downstream cyclone and to a separate area of WCB activity, located $30^{\circ}$ to $45^{\circ}$ downstream of the interaction point. This second cyclonic feature, located ahead of a trough downstream of the incipient ridge, deepens with time (Fig. 3g). A downstream WCB develops near this cyclone, together with a separate area of IVT located $50^{\circ}$ downstream of the interaction point: the irrotational outflow at the northern edge of this high IVT area contributes to the development of a second ridge $60^{\circ}$ downstream of the interaction point (Figs. 3g,h). The development of the downstream WCB is likely influenced by the enhanced moisture transport into downstream regions, related to the transitioning TC [Grams and Archambault (2016), see their Figs. S6 and S7].

On the other hand, in the TC-noRWI composite, the magnitude of the irrotational wind near the interaction point diminishes after $t_{\text {int }}$, and there is no signature of a ridgetrough couplet downstream of the interaction point as in TC-RWI (Figs. 3e, 4e). Instead, a broad, low-amplitude, southwest-northeast-oriented ridge expands downstream of the TC. The upstream anticyclone persists in the same location, and the TC moves along its southeastern boundary (Figs. 4e,g). Strong irrotational winds and WCB outflow, reflecting ascent and precipitation along the baroclinic zone, are not found in the region of the TC (as in the TC-RWI subset), but only $15^{\circ}-20^{\circ}$ downstream. Interestingly, the irrotational wind vectors diverge from the northward edge of a single, narrow IVT "tongue" emanating from the region of the TC, where the moisture interacts with the baroclinic zone and is able to ascend (Fig. 4f). The rapid downstream propagation of this area of diabatic outflow along the baroclinic zone resembles the formation of a diabatic Rossby wave (Boettcher and Wernli 2013) as reported, for example, for the ET of Typhoon Jangmi (Grams et al. 2013b). Two days after $t_{\text {int }}$, a broad area of WCB outflow is located approximately $60^{\circ}$ downstream of the interaction point (Fig. 4h) and is associated with a weak trough at UL (Fig. 4g). However, the absence of strong irrotational wind in the composite suggests that this WCB outflow is not related to in situ moist ascent, but has ascended earlier and then been advected downstream by the jet.

\section{c. Feature-based diagnostics}

The composite analysis revealed that the TC-RWI and TC-noRWI subsets differ in terms of jet structure and moisture transport. Next, we employ feature-based metrics to highlight the physical processes that are responsible for the differences between the two subsets.

We compute at each grid point the standardized differences between the composite values of the two subsets as

$$
\Delta x=\frac{\bar{x}_{\mathrm{ET}-\mathrm{noRWI}}-\bar{x}_{\mathrm{ET}-\mathrm{RWI}},}{\sigma_{\mathrm{TCSJI}}},
$$

where $\bar{x}_{\mathrm{ET}-\text { noRWI }}\left(\bar{x}_{\mathrm{ET}-\mathrm{RWI}}\right)$ is the composite value at every grid point of a given quantity for the TC-noRWI 

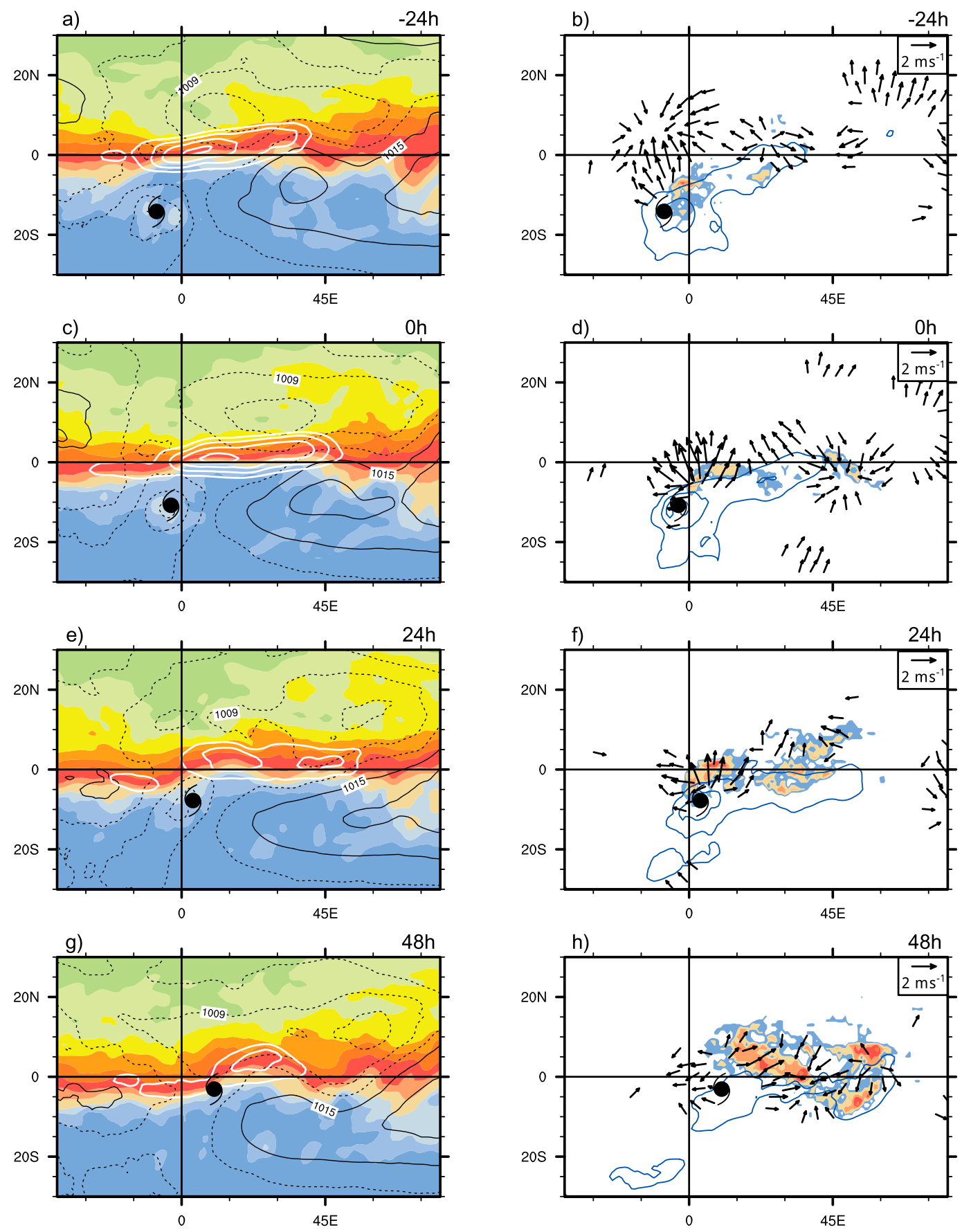

PVU

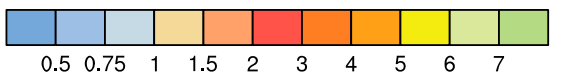

frequency

FIG. 3. Time-lagged composites (a),(b) $24 \mathrm{~h}$ before $t_{\text {int }}$; (c),(d) at $t_{\text {int }}$; and (e),(f) $24 \mathrm{~h}$ and (g),(h) $48 \mathrm{~h}$ after $t_{\text {int }}$ for $N=23$ TC-RWI cases, centered at the location of interaction. (left) PV composite (shaded, in PVU) and wind velocity (white contours, starting at $30 \mathrm{~m} \mathrm{~s}^{-1}$, every $5 \mathrm{~m} \mathrm{~s}^{-1}$ ) evaluated on the corresponding isentropic surfaces, SLP (black solid if or above $1015 \mathrm{hPa}$, dashed if below $1015 \mathrm{hPa}$, plotted every $3 \mathrm{hPa}$ ). (right) IVT (blue contours, only 400,600 , and $800 \mathrm{~kg} \mathrm{~m}^{-1} \mathrm{~s}^{-1}$ ), irrotational wind (vectors, only values $>1 \mathrm{~m} \mathrm{~s}^{-1}$ ), and frequency of WCB outflow (dimensionless [0,1], shaded). 

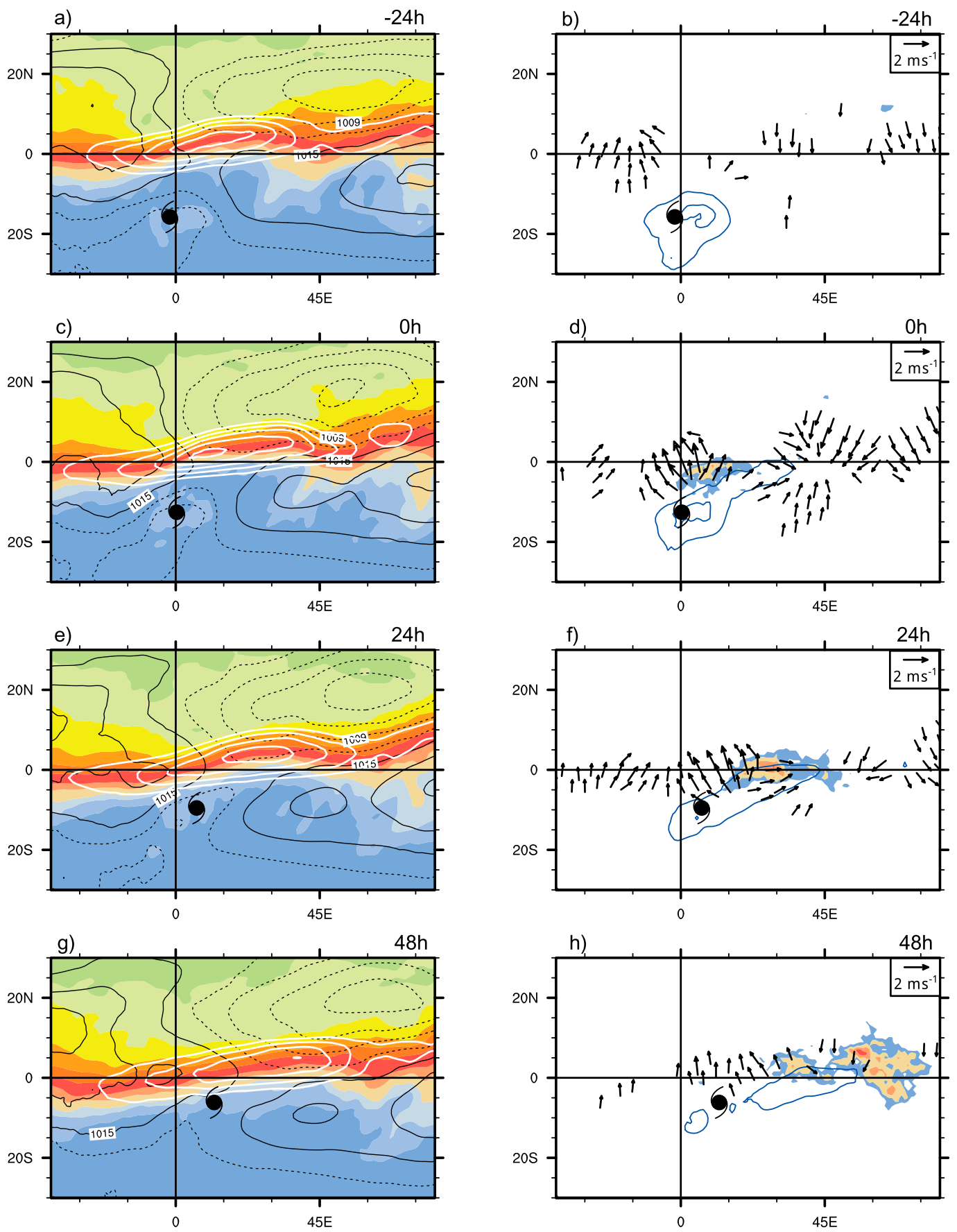

PVU

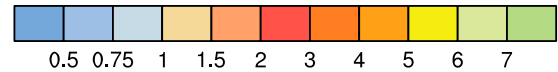

frequency

FIG. 4. As in Fig. 3, but for $N=52$ TC-noRWI cases.

(TC-RWI) subset, and $\sigma_{\mathrm{TCSJI}}$ is the standard deviation, relative to the same quantity at the same grid point, of the complete set of TCSJI. As pointed out by, for example, Torn et al. (2015), the use of standardized differences allows an easy comparison between different fields and vertical levels. Statistical significance is assessed using a bootstrapping approach: the set of TCSJI is shuffled 1500 times, and two subsets with the same number of elements as the TC-noRWI and TCRWI are randomly selected (without repetition) to obtain the distribution of the random standardized differences between the composites, under the null hypothesis 
that there is no difference between the two subsets. The difference between the composites is considered statistically significant if it exceeds at least the 95th percentile of the random distribution at each grid point.

Furthermore, some metrics (e.g., the areal average of a given quantity) are developed to quantify the influence of specific processes for specific flow features during each interaction. Thus, one value of a given metric is associated with each case, and the distributions of the two subsets can be compared using box-andwhisker diagrams. The statistical significance of the difference between the medians of the distributions is tested at the 95th percentile against the null hypothesis of no difference between the two values.

\section{1) CHARACTERISTICS OF THE UL FLOW}

The TC-RWI and TC-noRWI composites strongly differ in jet intensity at $t_{\text {int }}$. Wind speed on the considered isentropic levels is significantly higher (at the $95 \%$ confidence level) in TC-noRWI than in TC-RWI (Fig. 5a). The distribution of wind speed averaged at $t_{\text {int }}$ (Fig. 5b) in a $5^{\circ}$ latitudinal band along the $60^{\circ}$-long interaction segment (the light blue region along the 2-PVU contour in Fig. 5a) exhibits significantly higher values for TC-noRWI cases $\left(45-60 \mathrm{~m} \mathrm{~s}^{-1}\right)$ than TC-RWI $\left(35-50 \mathrm{~m} \mathrm{~s}^{-1}\right)$. The connection between the strength of the jet stream and flow amplification in the context of recurving TCs will be discussed in section $4 \mathrm{c}$.

In line with earlier studies (e.g., Deveson et al. 2002; Dacre and Gray 2009; Boettcher and Wernli 2011), we investigate the upper- and lower-level contribution to vertical motion in the midtroposphere $(600 \mathrm{hPa})$ using quasigeostrophic (QG) theory. Therefore, we inverted the $\mathbf{Q}$-vector form of the QG omega equation [see Davies (2015) for a review]. We discuss here the total QG-forced vertical motion at $600 \mathrm{hPa}(\omega)$ along with the component forced only from the lower levels $\left(1000-650 \mathrm{hPa}, \omega_{\mathrm{BOT}}\right)$. While differential vorticity advection is the main forcing for $\omega$ at ULs, low-level temperature advection is the main

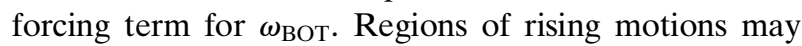
favor extratropical reintensification of the former TC (e.g., Agustí-Panareda 2008; Grams et al. 2013a) or strengthen the PV gradient at the tropopause (Lang and Martin 2013; Handlos and Martin 2016).

The total layer QG vertical motion at $600 \mathrm{hPa}$ for TCRWI (Fig. 6a) indicates strong ascent equatorward of the interaction point and to the southwest of the jet streak, but no clear signature of descent. In contrast, strong descent is found poleward of the interaction point, together with ascent farther south (Fig. 6b).

Forcing from lower levels supports this pattern (Figs. 6c,d). In both subsets, warm air advection at $850 \mathrm{hPa}$ between the TC and the neighboring subtropical anticyclone acts to increase thickness on the equatorward side of the jet. However, the northerly cold air advection in the TC-noRWI subset opposes such warm air advection: the resulting enhanced baroclinicity is associated with a strong, thermally direct circulation, reflected in the strong ascent/descent dipole at the entrance of the UL jet streak (Fig. 6b). This series of events recalls the process of jet superposition described for the WNP (albeit during winter; see Handlos and Martin 2016; Christenson et al. 2017). On the other hand, for TC-RWI, a dipole of cold air advection upstream and warm air advection downstream of the transitioning TC (contours in Fig. 6c) indicates the formation of low-level fronts during TCSJI. The absence of strong cold air advection at the poleward side of the jet allows ridge building and a northward displacement of the jet core.

\section{2) THE ROLE OF IRRotationAl AND NONDIVERGENT FLOW COMPONENTS}

The effect of diabatic outflow on the waveguide is evaluated using the PV advection by the irrotational component $-\mathbf{v}_{X} \cdot \nabla \mathrm{PV}$ and the nondivergent component $-\mathbf{v}_{\psi} \cdot \nabla \mathrm{PV}$ of the full wind. The irrotational wind $\mathbf{v}_{\chi}$ is obtained via Helmholtz partitioning, using a successive overrelaxation method, while the difference between the total wind and $\mathbf{v}_{\chi}$ is considered the nondivergent component of the wind $\mathbf{v}_{\psi}$. PV advection by the irrotational and by the nondivergent wind are averaged for every case along the interaction segment and in a layer $\pm 5 \mathrm{~K}$ above and below (the same blue area as in Fig. 5a) to obtain a representative metric of the flow component across the PV gradient at the tropopause at each time step. The layer average accounts for the uncertainty in the height of diabatic outflow. The instantaneous values of this along-segment, vertically integrated PV advection are finally averaged during $\Delta t_{\text {int }}$ to obtain a timeintegrated, representative value for each interaction.

In a region with a zonal jet, negative PV advection implies the displacement of low-PV air to regions where PV was originally higher and, hence, indicates the formation of a ridge. By the same argument, but conversely, positive PV advection would oppose ridge building. The algebraic sum of these two components gives the PV advection by the total wind $\left(v_{X}+v_{\psi}\right) \cdot \nabla \mathrm{PV}$, which takes into account both the contributions of $v_{\chi}$ and $v_{\psi}$.

The negative PV advection by the irrotational wind is offset by the positive PV advection by the nondivergent wind in the TC-noRWI cases (Figs. 5c,d). However, this is not the case for TC-RWI events, as generally, negative values of $\mathrm{PV}$ advection indicate overall ridge building (Fig. 5e). PV advection by the total wind is significantly different (at the 95th percentile) between the two subsets, whereas the distributions of PV 
(a) Wind speed difference

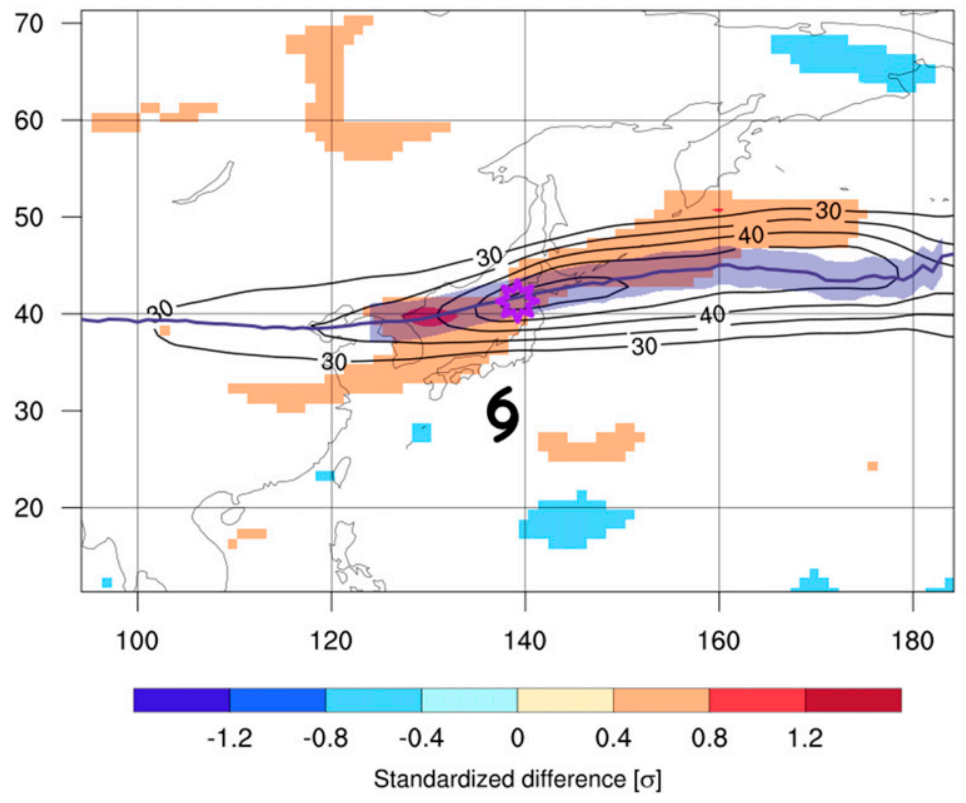

(c) PV advection by irrot. wind

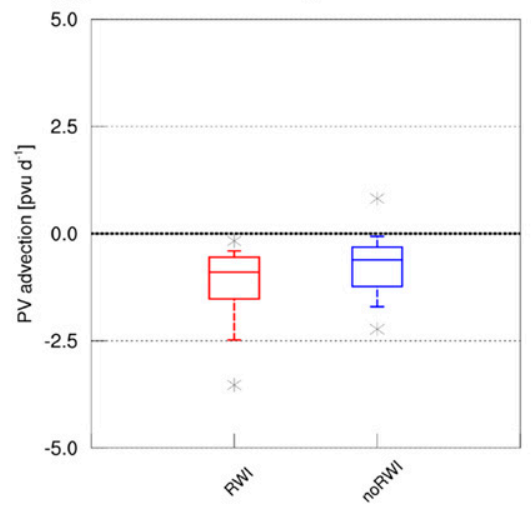

(d) PV advection by nondiv. wind

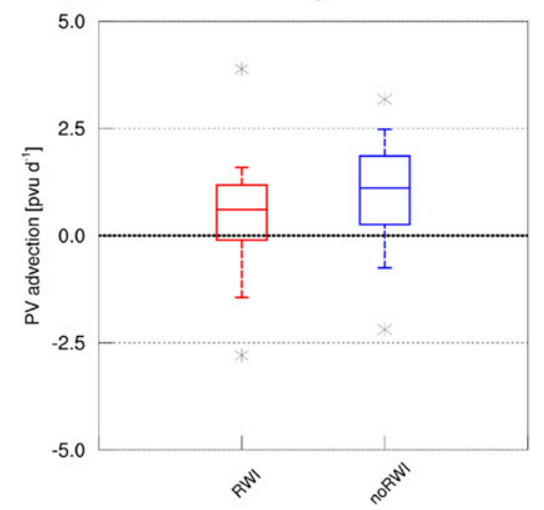

(b) Averaged jet speed

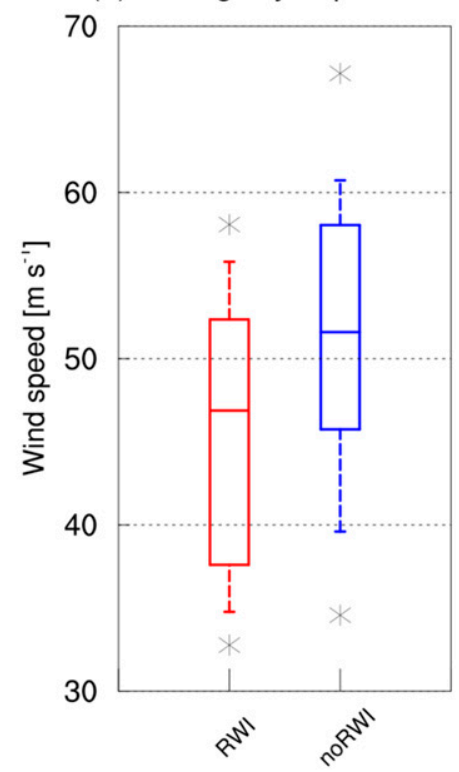

(e) PV advection sum

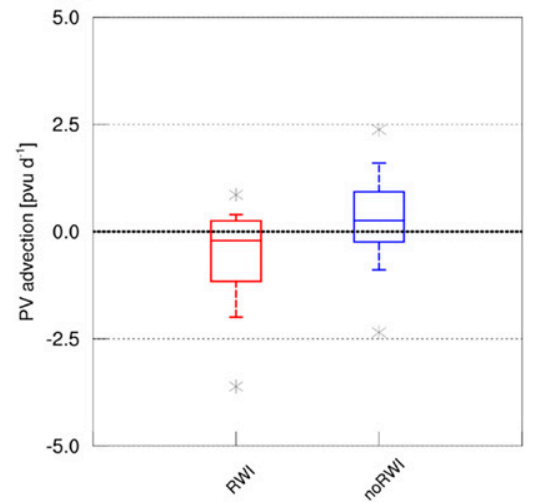

FIG. 5. (a) Composite of standardized, statistically significant (95th percentile) differences in wind speed between the TC-noRWI and the TC-RWI composite at $t_{\text {int }}$ on isentropic levels (shaded), centered at the location of interaction (purple star). Composite of wind speed (black contours starting at $30 \mathrm{~m} \mathrm{~s}^{-1}$, every $5 \mathrm{~m} \mathrm{~s}^{-1}$ ) and 2-PVU line (bold blue line) for all the TCSJIs are superimposed. The filled, light blue area along the 2-PVU line is $5^{\circ}$ wide and marks the average position of the interaction segment for all TCSJIs. Geographic boundaries and the average TC position for all TCSJIs (black TC symbol) are plotted for reference. Box-and-whisker diagrams (red for TC-RWI, blue for TC-noRWI) depicting (b) wind speed at $t_{\text {int }}\left(\mathrm{m} \mathrm{s}^{-1}\right)$ and PV advection (PVU day ${ }^{-1}$ ) by the (c) irrotational and (d) nondivergent component of the wind, averaged during $\Delta t_{\text {int }}$ in the filled blue area in (a) and vertically averaged on three isentropic levels (the selected one and the ones $5 \mathrm{~K}$ below and above). (e) PV advection by the total wind, sum of the two components depicted in (c),(d). The line across the box marks the median value, and the lower (upper) bound of the box shows the lower (upper) quartile. The lower (upper) whisker marks the lower (upper) decile, and the asterisks show the absolute minimum and maximum values.

advection by the irrotational and nondivergent winds feature no significant difference.

The relatively small differences of PV advection by the irrotational wind between the two subsets may seem surprising, as one might expect the strength of ridge building to be related to the strength of irrotational outflow of the TC (Archambault et al. 2013). Two annotations can be made to explain the relatively similar values of this metric. First, Helmholtz partitioning does not discriminate with respect to the cause of the irrotational wind, that is, whether the latter is related to a diabatically induced outflow or to the thermally direct, ageostrophic circulation at the jet streak entrance (which is stronger in TC-noRWI than in TC-RWI; Figs. 5b, 6b). Second, the strength of the $\mathrm{PV}$ advection by the irrotational wind is also related to 
(a) TC-RWI - w

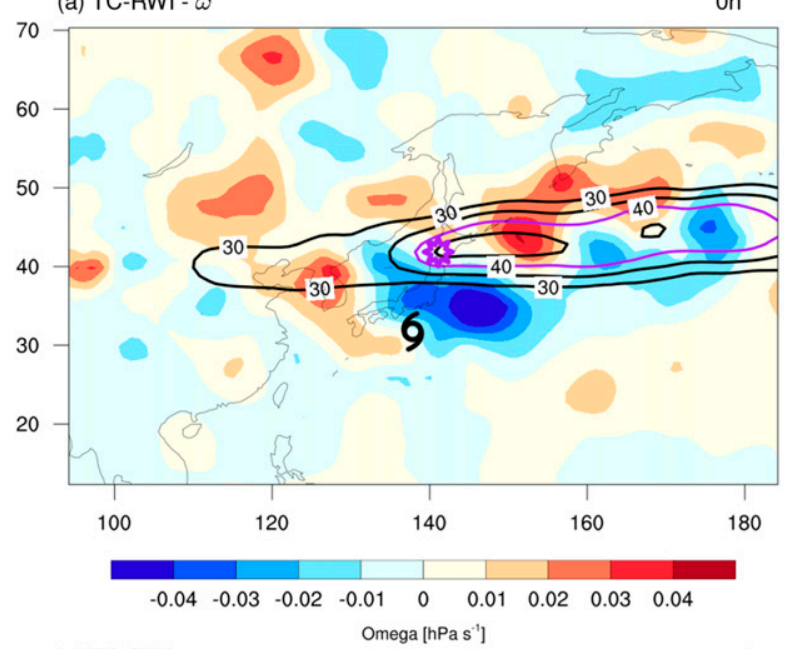

(c) TC-RWI - $\omega_{\mathrm{BOT}}$

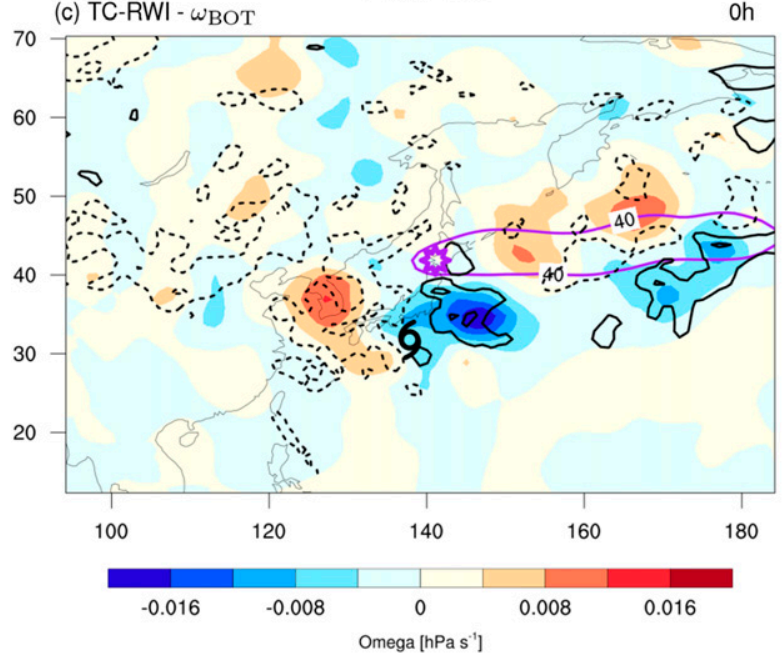

(b) TC-noRWI - $\omega$

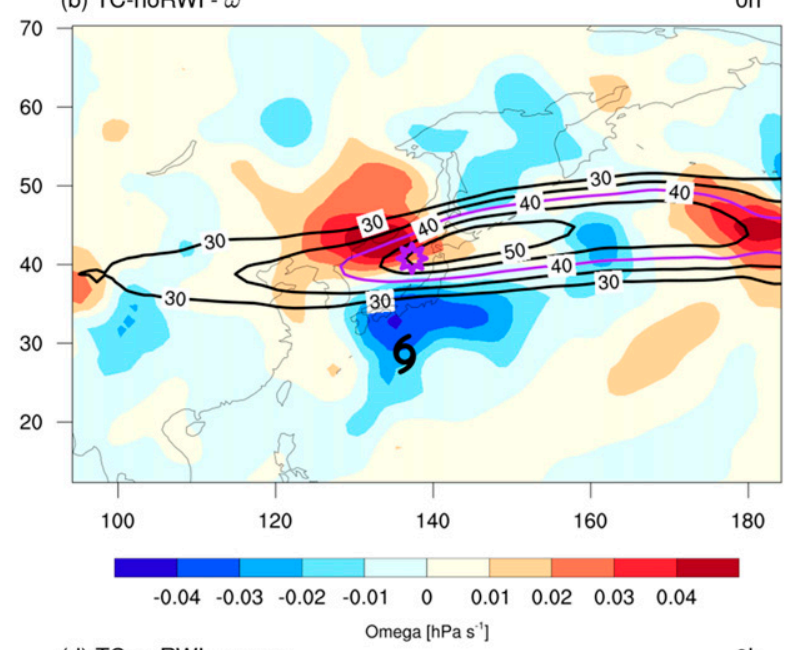

(d) TC-noRWI - $\omega_{\text {BOT }}$

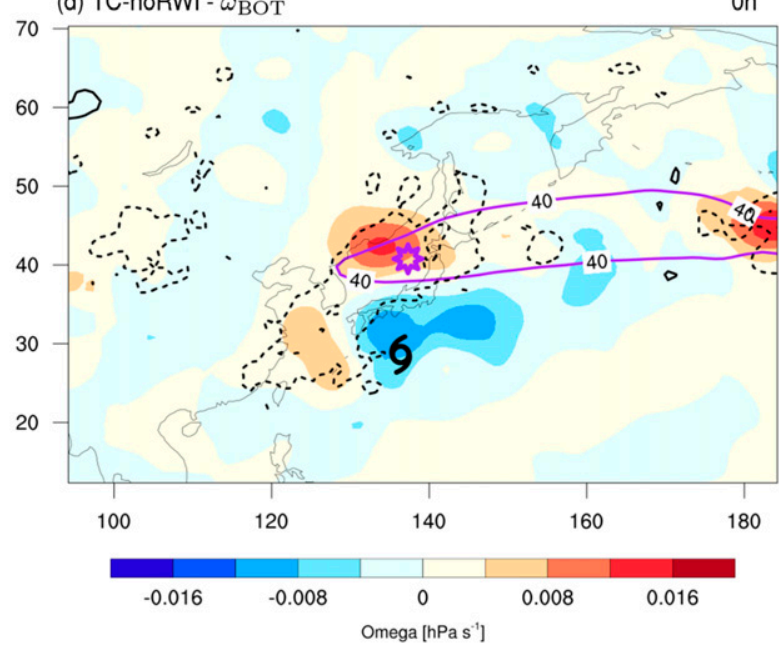

FIG. 6. Composites of QG vertical velocity at $600 \mathrm{hPa}\left(\mathrm{hPa} \mathrm{s}^{-1}\right.$, shaded), centered at the location of interaction (purple star) at $t_{\text {int }}$, forced by the layers (a),(b) 1000-200 ( $\omega)$ and (c),(d) 1000-650 hPa ( $\left.\omega_{\mathrm{BOT}}\right)$, for (left) TC-RWI and (right) TC-noRWI cases. Additionally, (a),(b) show wind speed on isentropic surfaces (black and purple contours, starting at $30 \mathrm{~m} \mathrm{~s}^{-1}$, every $5 \mathrm{~m} \mathrm{~s}^{-1}$, as in Figs. 3, 4); the $40 \mathrm{~m} \mathrm{~s}^{-1}$ isotach (purple contour) appears in all the plots. (c),(d) Temperature advection at $850 \mathrm{hPa}$ [black positive (negative) solid (dashed) contours; only the contours of $-5,-2,+2$, and $+5 \mathrm{~K} \mathrm{day}^{-1}$ are plotted].

the strength of the PV gradient, which is higher in TCnoRWI than in TC-RWI.

Therefore, we hypothesize that sustained, diabatically enhanced ridge building cannot occur because the strong jet stream related to TC-noRWI cases (Fig. 5b) rapidly advects downstream the negative PV anomaly associated with the irrotational, diabatic outflow. This is primarily due to the PV advection by the nondivergent wind and highlights the contribution of the balanced flow in determining the strength of ridge building during TCSJIs.

\section{3) Characteristics of THE TC}

There are no clear differences in the intensities of TCs leading to RWI and noRWI during $\Delta t_{\text {int }}$ (Fig. 7a). Before the interaction, TCs experience a weakening that is stronger for those in the TC-noRWI subset.

Deep layer wind shear (computed as the wind difference between 200 and $850 \mathrm{hPa}$ ) in the northern quadrant of the TC is similar between the two subsets and rather strong, given the vicinity of the jet stream (values larger than $25 \mathrm{~m} \mathrm{~s}^{-1}$; Fig. 7b). Such high values of wind shear induce steady weakening of the TCs in both subsets. The northerly advection of cold air in the TC-noRWI subset (depicted in Fig. 6d) reinforces this effect due to a strengthening of the lower-tropospheric shear (not shown). The presence of forcing for ascent at the right entrance of the zonal jet (Figs. 6a,b) is not able to compensate the detrimental effect of shear. However, there is a tendency to extratropical reintensification for TCs in 
(a) SLP time series

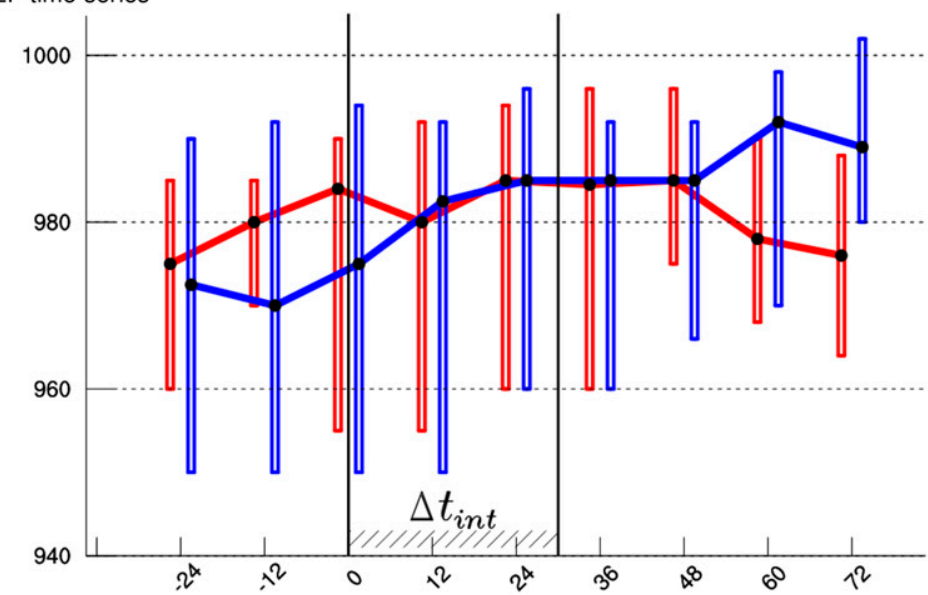

(b) Averaged wind shear

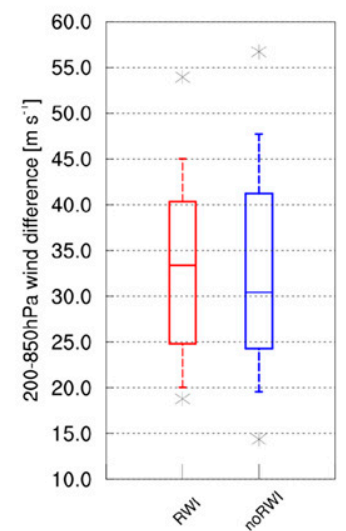

FIG. 7. (a) IBTrACS SLP minima of TCs in the TC-RWI (red) and TC-noRWI (blue) subsets (box-and-whisker diagrams). Black dots, connected by colored bold lines, highlight the median values, while the lower (upper) bound of the box shows the lower (upper) quartile. (b) Box-and-whisker diagrams (red for TC-RWI, blue for TC-noRWI) showing the magnitude of vertical wind shear between 850 and $200 \mathrm{hPa}$, averaged during $\Delta t_{\text {int }}$ in a fixed $10^{\circ} \times 10^{\circ}$ box north of the position of the TC at $t_{\text {int }}$ [dark blue in (b)]. Quantiles depicted in the box-and-whisker diagram in (b) are as in Fig. 5b.

the TC-RWI subset, which is evident only 2 days after $t_{\text {int }}$ (Fig. 7a).

\section{4) Characteristics OF THE LOW-LEVEL FLOW}

An anticyclone north of the recurving TC is a prominent feature of the TC-noRWI subset and marks a significant difference from the TC-RWI composite (Fig. 8a). We quantify this difference with the temporal and spatial average of SLP in a $15^{\circ} \times 15^{\circ}$ box upstream of the interaction point (gray in Fig. 8a) during $\Delta t_{\text {int }}$. Significantly (up to the 99th percentile) higher SLP upstream of the interaction location is observed for TC-noRWI (median: $1017 \mathrm{hPa}$ ) than for TC-RWI cases (median: $1010 \mathrm{hPa}$ ) (Fig. 8b).

This area of high pressure upstream of TC-noRWI cases adds a northerly component to the low-level flow in the vicinity of the interaction point. The anticyclonic circulation counteracts the meridional transport of moisture toward the waveguide by the recurving TC: the signature of the anticyclonic circulation on moisture transport at low levels is highlighted by the negative anomaly of moisture flux at $850 \mathrm{hPa}$ in the area between the TC and the interaction point (Fig. 8c). The moisture flux near the location of interaction is markedly higher for TC-RWI cases than for the TC-noRWI cases (Fig. 8d; moisture flux averaged in the dark green box in Fig. 8c). The availability of moisture is a prerequisite for convection and heavy precipitation, which in turn leads to diabatic outflow and flow amplification. It is therefore not surprising that the TC-noRWI subset is related to a reduced strength of ridge building. This aspect will be further discussed in section 4 (see also Fig. S1).

\section{Discussion}

Our study reveals that the interaction of a recurving TC with a zonally oriented jet does not necessarily yield the local initiation of a downstream-propagating Rossby wave. The strength of the jet stream and of the low-level moisture transport can modulate flow amplification. Here, we discuss in more detail how the variability of the regional circulation pattern, the direction of the largescale moisture transport, and the strength of the UL jet stream can hinder (or favor) midlatitude flow amplification during TCSJI.

\section{a. Seasonality of TC-RWI}

The phase of the East Asian monsoon (EAM; Yang et al. 2002; Ha et al. 2012) dictates the synoptic patterns of SLP during summer and fall over the region and modulates the transport of moisture from the tropics to the midlatitudes in the WNP basin. Early during the typhoon season (July and August; Fig. 9a), a weak thermal low over the Asian continent, related to the EAM, leads to prevailing southerly flow over the WNP. The situation is reversed during the late typhoon season (October and November; Fig. 9b), as the large-scale flow pattern gradually transitions into the cold phase of the EAM. This winter pattern of the EAM is governed by the presence of a strong and persistent surface anticyclone over the Asian continent, which induces northerly winds over the WNP (Fig. 9b). This circulation pattern is also characterized by large-scale deformation, as in TCnoRWI, and is connected with an increase of baroclinicity and a strengthening of the UL jet stream over 
(a) SLP difference

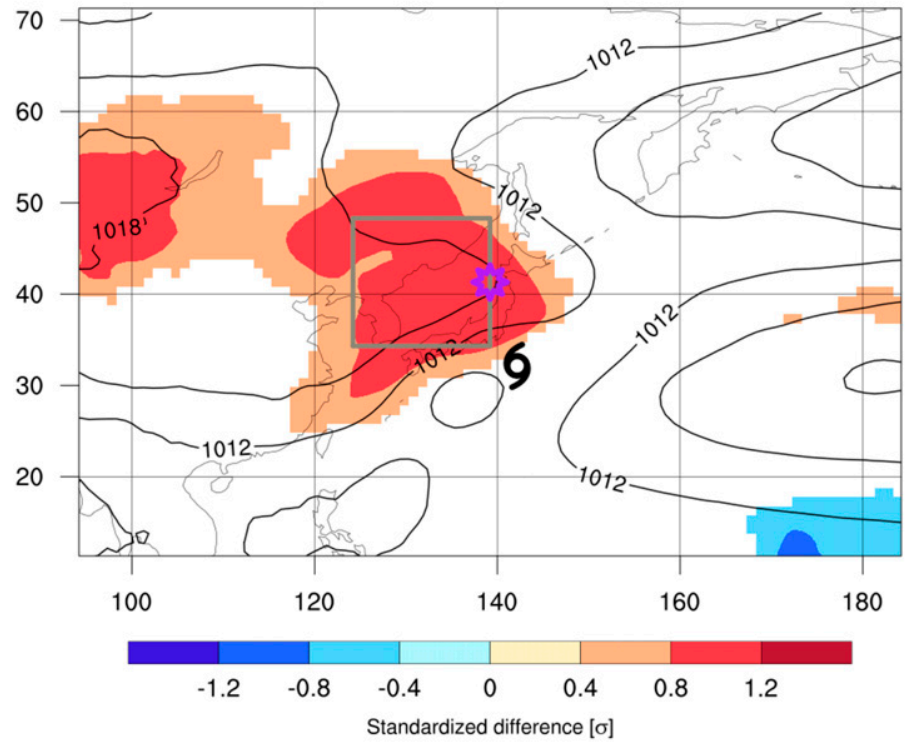

(c) $850 \mathrm{hPa}$ MF difference

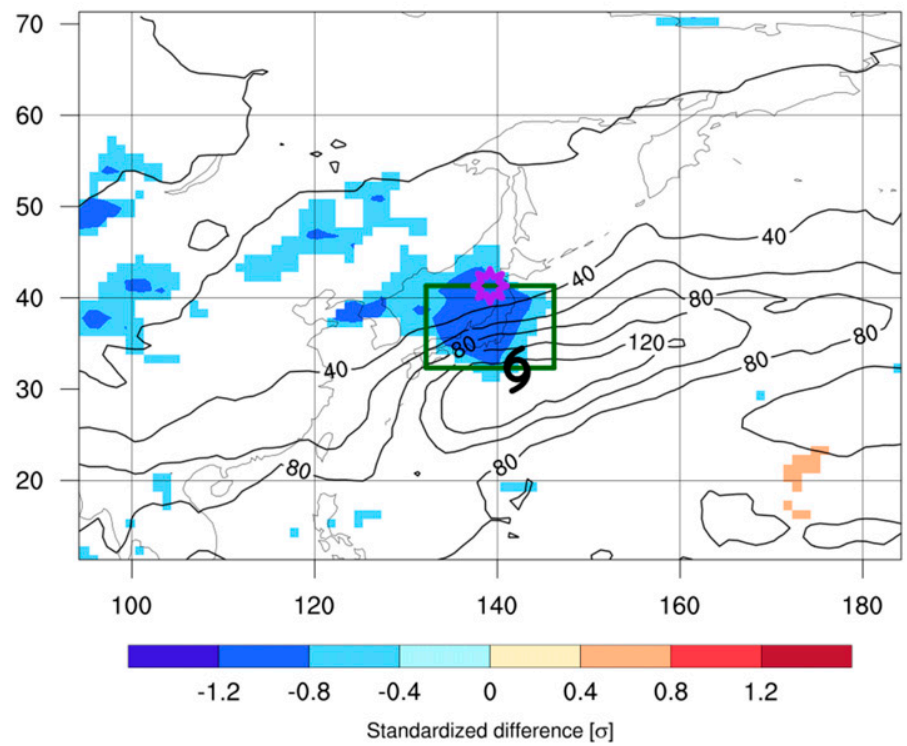

(b) Averaged SLP

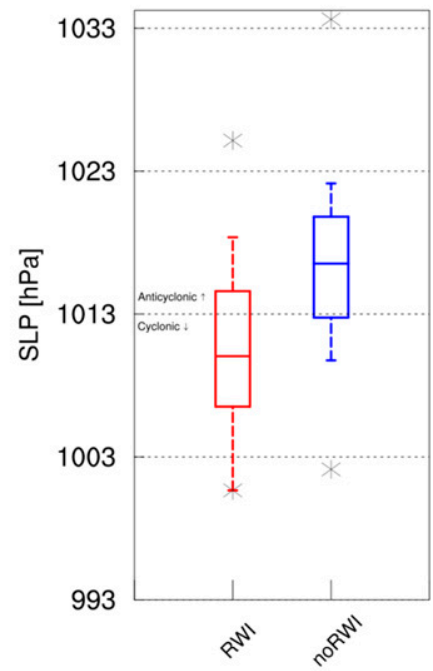

(d) Averaged $850 \mathrm{hPa}$ MF

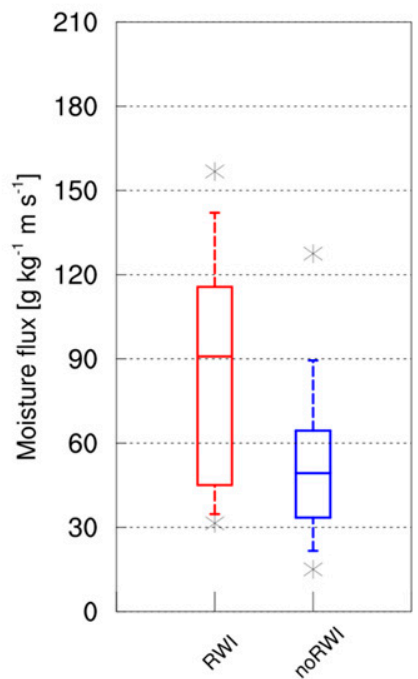

FIG. 8. (a) Composite of standardized, statistically significant (99th percentile) differences in SLP between the TC-noRWI and the TC-RWI composite $24 \mathrm{~h}$ after $t_{\text {int }}$ (shaded), centered at the location of interaction (purple star). The composite SLP for all TCSJIs (every $3 \mathrm{hPa}$, black contours) at the same time lag is superimposed. (b) Box-andwhisker diagrams (red for TC-RWI, blue for TC-noRWI) showing SLP during $\Delta t_{\text {int }}$, averaged in a fixed $15^{\circ} \times 15^{\circ}$ area west of the location of interaction [gray box in (a)]. (c) As in (a), but for moisture flux (MF) at $850 \mathrm{hPa}$. The composite MF for all TCSJIs at $850 \mathrm{hPa}$ at $t_{\text {int }}+24 \mathrm{~h}$ is superimposed ( $\mathrm{kg} \mathrm{m} \mathrm{s}^{-1}$, black contours). (d) As in (b), but for MF at $850 \mathrm{hPa}$, averaged during $\Delta t_{\text {int }}$ in a fixed $15^{\circ} \times 10^{\circ}$ box south of the location of interaction [dark green box in (c)]. Geographic boundaries in (a),(c) and the average TC position during all TCSJIs (bold, black TC symbol) are plotted for reference. Quantiles depicted in the box-and-whisker diagram in (b),(d) are as in Fig. 5b.

the WNP. Furthermore, northerly flow over the basin opposes the poleward transport of tropical moisture. Such unfavorable conditions can explain the very low frequency of TC-RWI events during October and November, despite the relatively high absolute numbers of recurving TCs in the same months. TCSJIs during October and November are indeed affected by a configuration of strong, anticyclonic, northerly flow (Fig. 4). The occasional interaction of recurving TCs with cold air outbreaks from the Asian continent is 

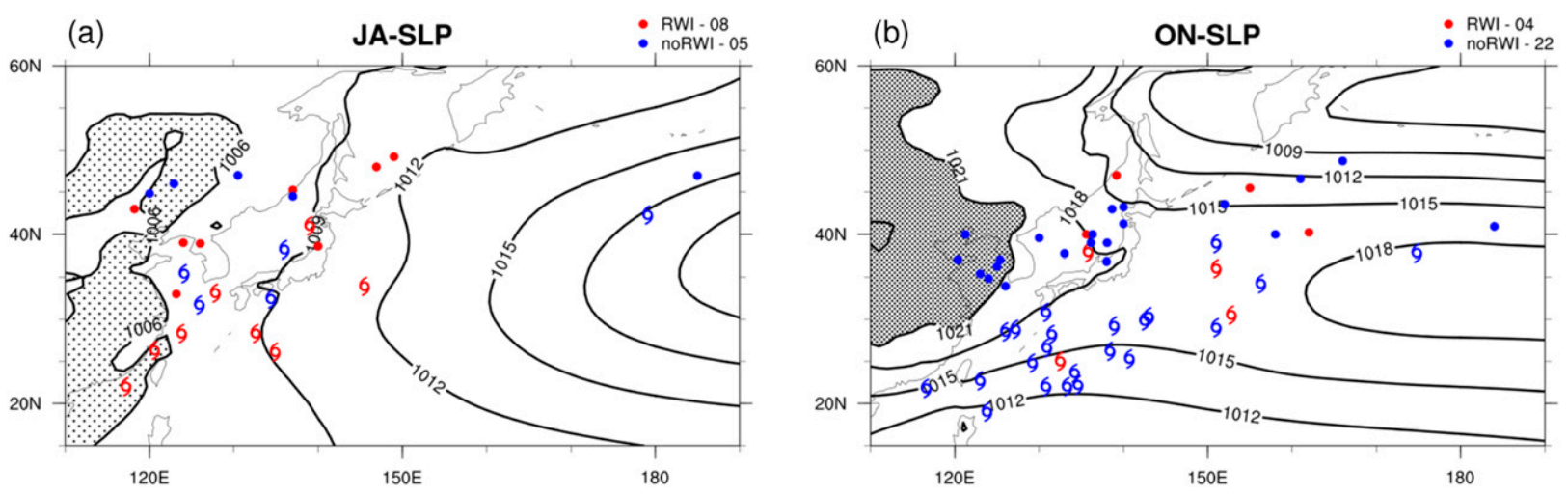

FIG. 9. ERA-Interim climatology of SLP in the WNP basin for the months of (a) July and August and (b) October and November (black contours, every $3 \mathrm{hPa}$ ). Stippling in the left (right) plot marks areas with SLP lower (higher) than $1006 \mathrm{hPa}(1021 \mathrm{hPa})$. Interaction locations (filled dots) and TC locations (TC symbols) at $t_{\text {int }}$ for the corresponding months are overlaid for TC-RWI (red) and TC-noRWI (blue) cases.

a characteristic feature of the basin and has been already documented in previous research (e.g., Matano and Sekioka 1971; Peng et al. 2014).

\section{b. Moisture transport during TC-noRWI cases}

The TC-noRWI composite exhibits a region of strong moisture transport on the equatorward side of the jet, highlighted by the narrow area of IVT in excess of $400 \mathrm{~kg} \mathrm{~m}^{-1} \mathrm{~s}^{-1}$ (Fig. 4f), which propagates downstream of the interaction location (Figs. 4d,f,h). This elongated moisture plume shares some characteristics with so-called atmospheric rivers (ARs), long and narrow atmospheric regions of intense water vapor transport that also feature IVT values higher than $400 \mathrm{~kg} \mathrm{~m}^{-1} \mathrm{~s}^{-1}$ (Ralph and Dettinger 2011). The case study of Cordeira et al. (2013) considered the genesis of ARs from recurving TCs. They described the development of two ARs originating from Typhoons Megi and Chaba in October 2010, which crossed the Pacific and lead to heavy rainfall over the mountainous regions of Northern California (Typhoon Chaba is part of the TC-noRWI set; see Table S2). The interaction of the TC with a baroclinic zone produced low-level vorticity anomalies along the front and promoted a low-level jet on its equatorward side [Cordeira et al. (2013), their Figs. 3, 4]. In our study, the coupling between the strong jet stream of TC-noRWI cases and the AR feature itself further intensifies the IVT along the baroclinic zone. We may thus speculate that TC-noRWI cases in our study are a favorable environment for the onset of ARs originating from recurving TCs.

\section{c. Jet intensity and flow amplification}

The group velocity of Rossby waves increases with the mean flow speed; therefore, a Rossby wave developing on a weak jet stream is associated with slower downstream propagation of wave activity than one developing on a strong jet stream (Rossby 1939).

The higher group velocity connected to a strong jet stream can hinder flow amplification in the context of TCSJI. Riemer et al. (2008) showed that the diabatic outflow of a recurving TC was able to initiate a Rossby wave only if it could impinge on the jet in the same area for a prolonged time. Therefore, a weak jet stream would be associated with a slower downstream propagation of the diabatically generated PV anomalies and make ridge building easier. This argument is consistent with TC-RWI events being associated with weaker jet speed than TC-noRWI cases (Figs. 5a,b). In contrast, in TC-noRWI cases, the diabatic outflow air mass is rapidly advected downstream by the strong westerly jet, and therefore, the resulting meridional jet displacement has a smaller magnitude near the region of diabatic outflow than in the case of TC-RWI. Hence, TCSJI during TC-noRWI events results only in a small increase of waviness along the considered segment.

The differentiation between TCs featuring a strong or weak downstream flow amplification is also reminiscent of the problem of "phasing" during ET, that is, of which conditions the midlatitude flow should fulfill to promote (or not) a strong downstream impact. The previously outlined results indicate that flow amplification is less likely to occur in an environment where a strong jet stream is present. The rapid propagation of the outflow PV anomaly in TC-noRWI cases does not allow the establishment of "phase locking" during TCSJI, in the sense that the negative PV anomaly induced by the outflow of the transitioning TC is not able to propagate against the background flow rapidly enough to remain in the vicinity of the TC and lead to localized, sustained ridge building. 

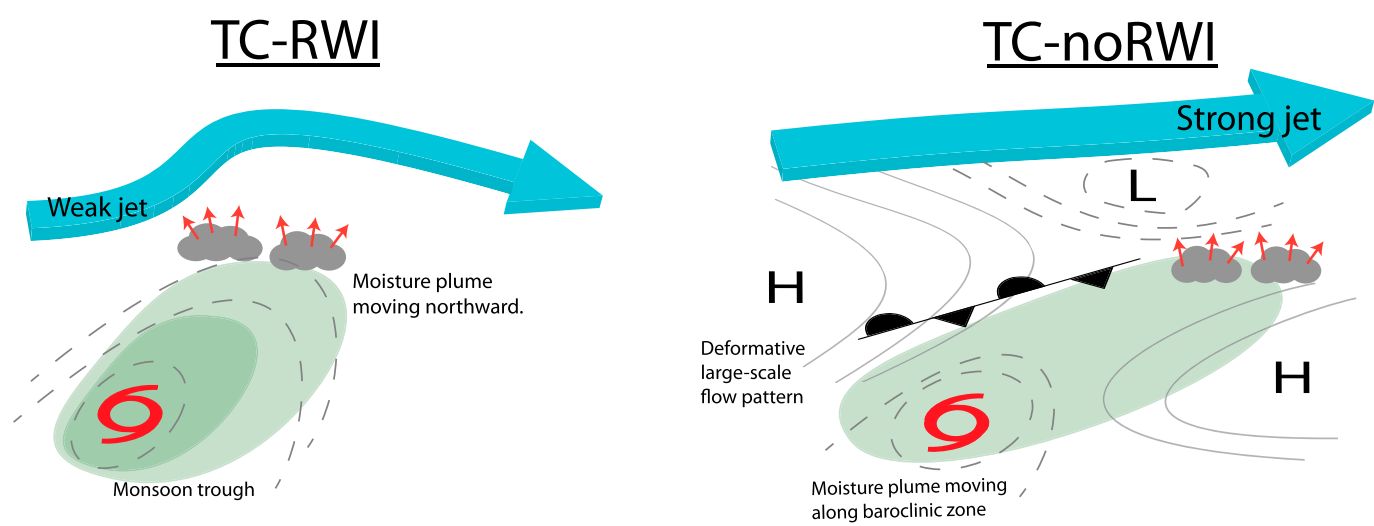

FIG. 10. Schematic depicting salient characteristics of (left) TC-RWI and (right) TC-noRWI events during the interaction period $\Delta t_{\text {int }}$. The UL jet stream is indicated by the $3 \mathrm{D}$ light blue arrow, while the low-level moisture plume associated with the recurving TC is shaded in green. The small gray clouds point to locations of ascent along the baroclinic zone (which is highlighted by the black frontal line for the TC-noRWI schematic), associated with convection and irrotational outflow. The anticyclones described in the TC-noRWI composite are depicted by the sketched gray isobars surrounding the $\mathrm{H}$ symbols; conversely, the monsoon trough embedding the TC and the cyclone downstream of TCSJI are outlined by dashed gray isobars around the TC symbol and the L symbol.

\section{d. A schematic view of RWI during ET}

The diabatic outflow linked to the TC is tightly connected to poleward displacements of the jet stream and to diabatically enhanced ridge building (Atallah and Bosart 2003; Galarneau 2015; Grams and Archambault 2016). A strong diabatic outflow in the vicinity of the jet can be achieved if there is sufficient supply of moisture and a forcing for ascent (both necessary for condensation of water vapor and latent heat release). Forcing for ascent is present equally near the TC in both cases (Figs. 6a,b); therefore, the availability of low-level moisture becomes crucial in a low-waviness configuration. Consistently with this argument, TCSJIs leading to RWI feature much higher values of IVT in the direction of the segment of interaction than TC-noRWI cases (e.g., Fig. 3e). Cloud systems ahead of the TC and the TC itself produce diabatic outflow and deflect the jet poleward (Fig. 10, left). This process continues during $\Delta t_{\text {int }}$ and deflects the jet poleward downstream of the interaction point. Incipient ridge building and jet streak formation promote downstream development, which takes place in a region of high IVT east of the transitioning TC.

The process of RWI due to the action of a recurving TC can be interrupted if the moisture is not able to move northward, in the direction of the waveguide, but is instead rapidly sheared away from the TC in a large-scale flow pattern characterized by deformation (Fig. 10, right). Interestingly, the axis of dilatation of such a "saddle point" pattern is roughly aligned with the jet axis and is rotated $\sim 90^{\circ}$ with respect to the UL deformation pattern that Röthlisberger et al. (2018) found to be associated with RWI more generally. This large-scale, frontogenetic flow pattern prevents the tropical moisture surrounding the TC from moving poleward, in the direction of the waveguide. The advection of cold air by the continental anticyclonic circulation, together with the warm air advection between the recurving TC and the subtropical anticyclone, strengthens the PV gradient at the tropopause along the interaction segment and, therefore, the jet stream. The strong jet is also related to strong vertical wind shear, which promotes a rapid decay of the TC circulation, while favoring the zonal transport of moisture along the low-level baroclinic zone rather than slantwise ascent. Moreover, as discussed in section $4 \mathrm{c}$, the strong jet stream does not allow sustained ridge building.

In synthesis, the large-scale flow pattern can support (in the case of TC-RWI) or hinder (in the case of TCnoRWI) the meridional transport of moisture and the subsequent release of latent heat in the region between the recurving TC and the jet stream. The amplitude of the incipient ridge building is then further modulated by the strength of the jet stream, which advects the diabatically generated PV anomalies more or less rapidly along the waveguide. The role played by the largescale, deformative flow pattern in promoting frontogenesis at tropopause level and hindering RWI still needs to be quantitatively analyzed and discussed and is a potentially interesting topic for future research.

\section{Conclusions}

This study presents a climatological analysis of the interactions between recurving TCs and zonally oriented waveguides in the WNP basin between 1979 and 
2013 and is also a first attempt to attribute a set of RWI cases to a specific initiation mechanism (i.e., the effect of a recurving TC).

The compiled climatology confirms that most recurving WNP TCs interact with a preamplified flow, that is, with preexisting large-amplitude UL troughs and ridges. Still, interactions between recurving TCs and zonally oriented waveguides occur commonly, with a climatological frequency of 2.1 per year. The adopted criteria led to the identification of 75 interactions on a total of 331 recurving TCs, that is, roughly one quarter of the recurving TCs in the basin.

The set of TCSJIs has been further divided into TCs leading to strong (TC-RWI) or to weak (TC-noRWI) downstream flow amplification: 23 were classified as TCRWI and 52 as TC-noRWI. Moreover, we show that the presence of a TC in the vicinity of a zonally oriented jet (without upstream waves) increases the likelihood of RWI by roughly a factor of 3, compared to climatology.

The strength of the recurving TC is not related to its ability to induce RWI: TCs approaching a zonally oriented waveguide experience a steady weakening, without significant differences between the TC-RWI and TC-noRWI subsets. Regardless of its intensity, a recurving TC can initiate a Rossby wave only if the large-scale midlatitude flow is conducive to RWI. For a TC-RWI event to occur, the synoptic pattern must not hinder meridional moisture transport; furthermore, TCRWI is favored in the presence of a comparatively weak zonal jet stream. Such conditions are more frequently met during the warm phase of the East Asian monsoon (June-August), which features a shallow, low-pressure system over the Asian continent and weak baroclinicity.

Still, the most frequent outcome of a TCSJI is a weakly undulated waveguide. Interactions classified as TC-noRWI feature a strong, zonally oriented UL jet stream and a deformative, large-scale circulation pattern that prevents tropical moisture from impinging directly on the low-level baroclinic zone, as well as from ascending and interacting with the waveguide. TCnoRWI most frequently occurs during the late typhoon season, when a continental anticyclone related to the beginning winter phase of the EAM induces a cold, dry, northerly flow over the basin, along with a stronger, southward-displaced jet core. In this configuration, tropical moisture is rapidly advected eastward along the low-level baroclinic zone. September is a month of transition from the warm to the cold monsoon phase and features both TC-RWI and TC-noRWI; it is also the month with the highest number of TCSJIs, mainly because of the large number of recurving TCs.

We therefore conclude that TC-related ab initio flow amplification in the WNP is modulated by the large-scale flow pattern, rather than related to the characteristics of recurving TCs themselves. Furthermore, the large-scale moisture distribution dictates the locations and the timing of flow amplification in situations when a UL trough is absent: this emphasizes the role of moist processes when a TC interacts with a weakly undulated flow.

Acknowledgments. We are very grateful to Heini Wernli, Olivia Martius, and Ron McTaggart-Cowan for the support in writing and revising the manuscript and to Michael Riemer for the very fruitful discussions about the consistency of the results. We are grateful to Julian Quinting for providing the code to compute the irrotational wind and to Michael Sprenger for the technical support. We also would like to thank Stephan Pfahl and the members of the Atmospheric Dynamics group at ETH Zurich for the interesting and useful discussions that helped to clarify the results. We thank three anonymous reviewers for the thoughtful criticisms and the encouraging comments to a previous version of the manuscript. The work of JR is supported by the ETH Zurich Foundation, in collaboration with Coop (ETH Research Grant 1014-1). CMG and MR acknowledge funding by the Swiss National Science Foundation (SNSF) via Grants PZ00P2_148177/1 and 200021_159905/1, respectively.

\section{REFERENCES}

Agustí-Panareda, A., 2008: The contribution of ex-Tropical Cyclone Gert (1999) toward the weakening of a midlatitude cyclogenesis event. Mon. Wea. Rev., 136, 2091-2111, https://doi.org/10.1175/ 2007MWR1637.1.

- C. D. Thorncroft, G. C. Craig, and S. L. Gray, 2004: The extratropical transition of Hurricane Irene (1999): A potential-vorticity perspective. Quart. J. Roy. Meteor. Soc., 130, 1047-1074, https://doi.org/10.1256/qj.02.140.

- S. L. Gray, G. C. Craig, and C. D. Thorncroft, 2005: The extratropical transition of Tropical Cyclone Lili (1996) and its crucial contribution to a moderate extratropical development. Mon. Wea. Rev., 133, 1562-1573, https://doi.org/10.1175/ MWR2935.1.

Archambault, H. M., L. F. Bosart, D. Keyser, and J. M. Cordeira, 2013: A climatological analysis of the extratropical flow response to recurving western North Pacific tropical cyclones. Mon. Wea. Rev., 141, 2325-2346, https://doi.org/10.1175/ MWR-D-12-00257.1.

_ D. Keyser, L. F. Bosart, C. A. Davis, and J. M. Cordeira, 2015: A composite perspective of the extratropical flow response to recurving western North Pacific tropical cyclones. Mon. Wea. Rev., 143, 1122-1141, https://doi.org/10.1175/MWR-D-14-00270.1.

Atallah, E. H., and L. F. Bosart, 2003: The extratropical transition and precipitation distribution of Hurricane Floyd (1999). Mon. Wea. Rev., 131, 1063-1081, https://doi.org/10.1175/1520-0493 (2003)131<1063:TETAPD>2.0.CO;2.

Barton, Y., P. Giannakaki, H. von Waldow, C. Chevalier, S. Pfahl, and O. Martius, 2016: Clustering of regional-scale extreme 
precipitation events in southern Switzerland. Mon. Wea. Rev., 144, 347-369, https://doi.org/10.1175/MWR-D-15-0205.1.

Boettcher, M., and H. Wernli, 2011: Life cycle study of a diabatic Rossby wave as a precursor to rapid cyclogenesis in the North Atlantic-Dynamics and forecast performance. Mon. Wea. Rev., 139, 1861-1878, https://doi.org/10.1175/2011MWR3504.1.

, and - 2013: A 10-yr climatology of diabatic Rossby waves in the Northern Hemisphere. Mon. Wea. Rev., 141, 1139-1154, https://doi.org/10.1175/MWR-D-12-00012.1.

Cavallo, S. M., and G. J. Hakim, 2009: Potential vorticity diagnosis of a tropopause polar cyclone. Mon. Wea. Rev., 137, 13581371, https://doi.org/10.1175/2008MWR2670.1.

Christenson, C. E., J. E. Martin, and Z. J. Handlos, 2017: A synoptic climatology of Northern Hemisphere, cold season polar and subtropical jet superposition events. J. Climate, 30, 72317246, https://doi.org/10.1175/JCLI-D-16-0565.1.

Cordeira, J. M., F. M. Ralph, and B. J. Moore, 2013: The development and evolution of two atmospheric rivers in proximity to western North Pacific tropical cyclones in October 2010. Mon. Wea. Rev., 141, 4234-4255, https://doi.org/10.1175/ MWR-D-13-00019.1.

Dacre, H. F., and S. L. Gray, 2009: The spatial distribution and evolution characteristics of North Atlantic cyclones. Mon. Wea. Rev., 137, 99-115, https://doi.org/10.1175/ 2008MWR2491.1.

Davies, H. C., 2015: The quasigeostrophic omega equation: Reappraisal, refinements, and relevance. Mon. Wea. Rev., 143, 3-25, https://doi.org/10.1175/MWR-D-14-00098.1.

—, and A. M. Rossa, 1998: PV frontogenesis and uppertropospheric fronts. Mon. Wea. Rev., 126, 1528-1539, https:// doi.org/10.1175/1520-0493(1998)126<1528:PFAUTF >2.0.CO;2.

— error growth. Mon. Wea. Rev., 141, 2483-2501, https://doi.org/ 10.1175/MWR-D-12-00242.1.

Dee, D. P., and Coauthors, 2011: The ERA-Interim reanalysis: Configuration and performance of the data assimilation system. Quart. J. Roy. Meteor. Soc., 137, 553-597, https://doi.org/ 10.1002/qj.828.

Deveson, A. C. L., K. A. Browning, and T. D. Hewson, 2002: A classification of FASTEX cyclones using a heightattributable quasi-geostrophic vertical-motion diagnostic. Quart. J. Roy. Meteor. Soc., 128, 93-117, https://doi.org/ 10.1256/00359000260498806.

Galarneau, T. J., Jr., 2015: Influence of a predecessor rain event on the track of Tropical Cyclone Isaac (2012). Mon. Wea. Rev., 143, 3354-3376, https://doi.org/10.1175/MWR-D-15-0053.1.

Grams, C. M., and H. M. Archambault, 2016: The key role of diabatic outflow in amplifying the midlatitude flow: A representative case study of weather systems surrounding western North Pacific extratropical transition. Mon. Wea. Rev., 144, 3847-3869, https://doi.org/10.1175/MWR-D-15-0419.1.

— S. C. Jones, C. A. Davis, P. A. Harr, and M. Weissmann, 2013a: The impact of Typhoon Jangmi (2008) on the midlatitude flow. Part I: Upper-level ridgebuilding and modification of the jet. Quart. J. Roy. Meteor. Soc., 139, 2148-2164, https://doi.org/10.1002/qj.2091.

,-- , and $-2013 \mathrm{~b}$ : The impact of Typhoon Jangmi (2008) on the midlatitude flow. Part II: Downstream evolution. Quart. J. Roy. Meteor. Soc., 139, 2165-2180, https://doi.org/ 10.1002/qj.2119.

Grazzini, F., and F. Vitart, 2015: Atmospheric predictability and Rossby wave packets. Quart. J. Roy. Meteor. Soc., 141, 27932802, https://doi.org/10.1002/qj.2564.
Ha, K.-J., K.-Y. Heo, S.-S. Lee, K.-S. Yun, and J.-G. Jhun, 2012: Variability in the East Asian monsoon: A review. Meteor. Appl., 19, 200-215, https://doi.org/10.1002/met.1320.

Hakim, G. J., 2005: Vertical structure of midlatitude analysis and forecast errors. Mon. Wea. Rev., 133, 567-578, https://doi.org/ 10.1175/MWR-2882.1.

Handlos, Z. J., and J. E. Martin, 2016: Composite analysis of largescale environments conducive to western Pacific polar/subtropical jet superposition. J. Climate, 29, 7145-7165, https:// doi.org/10.1175/JCLI-D-16-0044.1.

Harr, P. A., and J. M. Dea, 2009: Downstream development associated with the extratropical transition of tropical cyclones over the western North Pacific. Mon. Wea. Rev., 137, 12951319, https://doi.org/10.1175/2008MWR2558.1.

_ , and H. M. Archambault, 2016: Dynamics, predictability, and high-impact weather associated with the extratropical transition of tropical cyclones. Dynamics and Predictability of LargeScale, High-Impact Weather and Climate Events, J. Li et al., Eds., Cambridge University Press, 153-167, https://doi.org/ 10.1017/CBO9781107775541.013.

_ , R. L. Elsberry, and T. F. Hogan, 2000: Extratropical transition of tropical cyclones over the western North Pacific. Part II: The impact of midlatitude circulation characteristics. Mon. Wea. Rev., 128, 2634-2653, https://doi.org/10.1175/1520-0493 (2000) $128<2634$ :ETOTCO $>2.0$. CO; 2 .

Hart, R. E., 2011: An inverse relationship between aggregate Northern Hemisphere tropical cyclone activity and subsequent winter climate. Geophys. Res. Lett., 38, L01705, https://doi.org/10.1029/2010GL045612.

Hoskins, B. J., and T. Ambrizzi, 1993: Rossby wave propagation on a realistic longitudinally varying flow. J. Atmos. Sci., 50, 1661-1671, https://doi.org/10.1175/1520-0469(1993)050<1661: RWPOAR $>2.0 . \mathrm{CO} ; 2$.

— M. E. McIntyre, and A. W. Robertson, 1985: On the use and significance of isentropic potential vorticity maps. Quart. J. Roy. Meteor. Soc., 111, 877-946, https://doi.org/10.1002/ qj.49711147002.

Keller, J. H., S. C. Jones, and P. A. Harr, 2014: An eddy kinetic energy view of physical and dynamical processes in distinct forecast scenarios for the extratropical transition of two tropical cyclones. Mon. Wea. Rev., 142, 2751-2771, https://doi.org/ 10.1175/MWR-D-13-00219.1.

Klein, P. M., P. A. Harr, and R. L. Elsberry, 2002: Extratropical transition of western North Pacific tropical cyclones: Midlatitude and tropical cyclone contributions to reintensification. Mon. Wea. Rev., 130, 2240-2259, https://doi.org/10.1175/1520-0493(2002)130<2240: ETOWNP $>2.0 . \mathrm{CO} ; 2$.

Knapp, K. R., M. C. Kruk, D. H. Levinson, H. J. Diamond, and C. J. Neumann, 2010: The International Best Track Archive for Climate Stewardship (IBTrACS): Unifying tropical cyclone data. Bull. Amer. Meteor. Soc., 91, 363-376, https://doi.org/ 10.1175/2009BAMS2755.1.

Lang, A. A., and J. E. Martin, 2013: The structure and evolution of lower stratospheric frontal zones. Part II: The influence of tropospheric ascent on lower stratospheric frontal development. Quart. J. Roy. Meteor. Soc., 139, 1798-1809, https://doi.org/10.1002/qj.2074.

Lee, S., and I. M. Held, 1993: Baroclinic wave packets in models and observations. J. Atmos. Sci., 50, 1413-1428, https://doi.org/ 10.1175/1520-0469(1993)050<1413:BWPIMA > 2.0.CO;2.

Madonna, E., H. Wernli, H. Joos, and O. Martius, 2014: Warm conveyor belts in the ERA-Interim dataset (1979-2010). Part I: Climatology and potential vorticity evolution. J. Climate, 27, 3-26, https://doi.org/10.1175/JCLI-D-12-00720.1. 
Martínez-Alvarado, O., S. L. Gray, and J. Methven, 2016: Diabatic processes and the evolution of two contrasting summer extratropical cyclones. Mon. Wea. Rev., 144, 3251-3276, https:// doi.org/10.1175/MWR-D-15-0395.1.

Martius, O., C. Schwierz, and H. C. Davies, 2010: Tropopause-level waveguides. J. Atmos. Sci., 67, 866-879, https://doi.org/ 10.1175/2009JAS2995.1.

Massacand, A. C., H. Wernli, and H. C. Davies, 1998: Heavy precipitation on the alpine southside: An upper-level precursor. Geophys. Res. Lett., 25, 1435-1438, https://doi.org/10.1029/98GL50869.

Matano, H., and M. Sekioka, 1971: Some aspects of extratropical transformation of a tropical cyclone. J. Meteor. Soc. Japan, 49A, 736-743, https://doi.org/10.2151/jmsj1965.49A.0_736.

Orlanski, I., and J. P. Sheldon, 1995: Stages in the energetics of baroclinic systems. Tellus, 47A, 605-628, https://doi.org/ 10.3402/tellusa.v47i5.11553

Pantillon, F., J.-P. Chaboureau, and E. Richard, 2016: Vortexvortex interaction between Hurricane Nadine (2012) and an Atlantic cut-off dropping the predictability over the Mediterranean. Quart. J. Roy. Meteor. Soc., 142, 419-432, https:// doi.org/10.1002/qj.2635.

Peng, S., and Coauthors, 2014: On the mechanisms of the recurvature of Super Typhoon Megi. Sci. Rep., 4, 4451, https:// doi.org/10.1038/srep04451.

Quinting, J. F., and S. C. Jones, 2016: On the impact of tropical cyclones on Rossby wave packets: A climatological perspective. Mon. Wea. Rev., 144, 2021-2048, https://doi.org/10.1175/ MWR-D-14-00298.1.

Ralph, F. M., and M. D. Dettinger, 2011: Storms, floods, and the science of atmospheric rivers. Eos, Trans. Amer. Geophys. Union, 92, 265-266, https://doi.org/10.1029/2011EO320001.

Riemer, M., and S. C. Jones, 2014: Interaction of a tropical cyclone with a high-amplitude, midlatitude wave pattern: Waviness analysis, trough deformation and track bifurcation. Quart. J. Roy. Meteor. Soc., 140, 1362-1376, https://doi.org/10.1002/qj.2221.

- - , and C. A. Davis, 2008: The impact of extratropical transition on the downstream flow: An idealized modelling study with a straight jet. Quart. J. Roy. Meteor. Soc., 134, 69-91, https://doi.org/10.1002/qj.189.

_ , M. Baumgart, and S. Eiermann, 2014: Cyclogenesis downstream of extratropical transition analyzed by Q-vector partitioning based on flow geometry. J. Atmos. Sci., 71, 42044220, https://doi.org/10.1175/JAS-D-14-0023.1.

Ritchie, E. A., and R. L. Elsberry, 2007: Simulations of the extratropical transition of tropical cyclones: Phasing between the upper-level trough and tropical cyclones. Mon. Wea. Rev., 135, 862-876, https://doi.org/10.1175/MWR3303.1.

Rodwell, M. J., and Coauthors, 2013: Characteristics of occasional poor medium-range weather forecasts for Europe. Bull. Amer. Meteor Soc., 94, 1393-1405, https://doi.org/10.1175/BAMS-D-12-00099.1.
Rossby, C.-G., 1939: Relation between variations in the intensity of the zonal circulation of the atmosphere and the displacements of the semi-permanent centers of action. J. Mar. Res., 2, 38-55.

Röthlisberger, M., O. Martius, and H. Wernli, 2016a: An algorithm for identifying the initiation of synoptic-scale Rossby waves on potential vorticity waveguides. Quart. J. Roy. Meteor. Soc., 142, 889-900, https://doi.org/10.1002/qj.2690.

S. Pfahl, and O. Martius, 2016b: Regional-scale jet waviness modulates the occurrence of midlatitude weather extremes. Geophys. Res. Lett., 43, 10 989-10 997, https://doi.org/10.1002/ 2016GL070944.

— O. Martius, and H. Wernli, 2018: Northern Hemisphere Rossby wave initiation events on the extratropical jet-A climatological analysis. J. Climate, 31, 743-760, https://doi.org/ 10.1175/JCLI-D-17-0346.1.

Scheck, L., S. C. Jones, and M. Juckes, 2011: The resonant interaction of a tropical cyclone and a tropopause front in a barotropic model. Part I: Zonally oriented front. J. Atmos. Sci., 68, 405-419, https://doi.org/10.1175/2010JAS3482.1.

Screen, J. A., and I. Simmonds, 2014: Amplified mid-latitude planetary waves favour particular regional weather extremes. Nat. Climate Change, 4, 704-709, https://doi.org/ 10.1038/nclimate2271.

Sprenger, M., and Coauthors, 2017: Global climatologies of Eulerian and Lagrangian flow features based on ERAInterim. Bull. Amer. Meteor. Soc., 98, 1739-1748, https://doi.org/ 10.1175/BAMS-D-15-00299.1.

Stensrud, D. J., 2013: Upscale effects of deep convection during the North American monsoon. J. Atmos. Sci., 70, 2681-2695, https://doi.org/10.1175/JAS-D-13-063.1.

Torn, R. D., and G. J. Hakim, 2015: Comparison of wave packets associated with extratropical transition and winter cyclones. Mon. Wea. Rev., 143, 1782-1803, https://doi.org/10.1175/ MWR-D-14-00006.1.

, J. S. Whitaker, P. Pegion, T. M. Hamill, and G. J. Hakim, 2015: Diagnosis of the source of GFS medium-range track errors in Hurricane Sandy (2012). Mon. Wea. Rev., 143, 132-152, https://doi.org/10.1175/MWR-D-14-00086.1.

Winters, A. C., and J. E. Martin, 2016: Synoptic and mesoscale processes supporting vertical superposition of the polar and subtropical jets in two contrasting cases. Quart. J. Roy. Meteor. Soc., 142, 1133-1149, https://doi.org/10.1002/qj.2718.

Wolf, G., and V. Wirth, 2017: Diagnosing the horizontal propagation of Rossby wave packets along the midlatitude waveguide. Mon. Wea. Rev., 145, 3247-3264, https://doi.org/ 10.1175/MWR-D-16-0355.1.

Yang, S., K.-M. Lau, and K.-M. Kim, 2002: Variations of the East Asian jet stream and Asian-Pacific-American winter climate anomalies. J. Climate, 15, 306-325, https://doi.org/10.1175/ 1520-0442(2002)015<0306:VOTEAJ > 2.0.CO;2. 